\title{
A Multi-Sectoral Approach Improves Early Child Development in a Disadvantaged Community in Peru: Role of Community Gardens, Nutrition Workshops and Enhanced Caregiver-Child Interaction: Project "Wawa Illari"
}

OPEN ACCESS

Edited by:

Jane Fisher,

Monash University, Australia

Reviewed by:

Laura Nabors,

University of Cincinnati, United States Nihar Ranjan Mishra,

Veer Surendra Sai Medical College

and Hospital, India

${ }^{*}$ Correspondence:

Kristine G. Koski

kristine.koski@mcgill.ca

Specialty section

This article was submitted to

Children and Health,

a section of the journal

Frontiers in Public Health

Received: 30 May 2020 Accepted: 06 October 2020 Published: 06 November 2020

Citation:

González-Fernández D, Mazzini

Salom AS, Herrera Bendezu F,

Huamán S, Rojas Hernández $B$,

Pevec I, Galarza Izquierdo EM,

Armstrong N, Thomas V, Vela Gonzáles S, Gonzáles Saravia C, Scott ME and Koski KG (2020) A

Multi-Sectoral Approach Improves

Early Child Development in a Disadvantaged Community in Peru: Role of Community Gardens, Nutrition

Workshops and Enhanced

Caregiver-Child Interaction: Project

"Wawa Illari".

Front. Public Health 8:567900.

doi: 10.3389/fpubh.2020.567900
Doris González-Fernández ${ }^{1}$, Ana Sofía Mazzini Salom ${ }^{2}$, Fermina Herrera Bendezu², Sonia Huamán ${ }^{3}$, Bertha Rojas Hernández ${ }^{4}$, Illène Pevec ${ }^{5}$, Eliana Mariana Galarza Izquierdo ${ }^{6}$, Nicoletta Armstrong ${ }^{7}$, Virginia Thomas ${ }^{8}$, Sonia Vela Gonzáles ${ }^{9}$, Carlos Gonzáles Saravia ${ }^{10}$, Marilyn E. Scott ${ }^{11}$ and Kristine G. Koski ${ }^{1 *}$

${ }^{1}$ School of Human Nutrition, McGill University, Sainte Anne de Bellevue, QC, Canada, ${ }^{2}$ International Child Development Program - ICDP Peru, Lima, Peru, ${ }^{3}$ Pachacámac Health Center, Ministry of Health, Lima, Peru, ${ }^{4}$ Laboratory School, Faculty of Medical Technology, Federico Villarreal National University, Lima, Peru, ${ }^{5}$ Community Engagement, Design and Research Center (CEDaR), University of Colorado, Boulder, CO, United States, " "Vivir" Association, Quito, Ecuador, ${ }^{7}$ International Child Development Program (ICDP), Oslo, Norway, ${ }^{8}$ Susila Dharma International Association, Greenfield Park, QC, Canada,

${ }^{9}$ Nursing School, Inca Garcilaso de la Vega University, Lima, Peru, ${ }^{10}$ Dermatology Service, Department of Medicine, National Institute for Children's Health (INSN), Lima, Peru, ${ }^{11}$ Institute of Parasitology, McGill University, Sainte Anne de Bellevue, QC, Canada

Background: Multi-dimensional monitoring evaluation and learning strategies are needed to address the complex set of factors that affect early child development in marginalized populations, but few studies have explored their effectiveness.

Objective: To compare improvement of health and development of children 0-3 years between intervention communities (IC) and control communities (CC) from peripheral settlements of Lima. Sequential interventions included: (1) home and community gardens, (2) conscious nutrition, and (3) parenting workshops following the International Child Development Program (ICDP).

Methods: Interventions were delivered by community health promoters (CHPs) using a "step-by-step" learning system. Both IC and CC were monitored before the interventions began, at 8 and 12 months ( $n=113 \mathrm{IC}$ and $127 \mathrm{CC}$ children). Data were collected on household characteristics, diet, food security, health indicators (history of diarrhea and respiratory infections, hemoglobin, intestinal parasites, anthropometry), caregiver-child interactions and stress, and achievement of Pan-American Health Organization age-specific developmental milestones. Stepwise multiple logistic regressions were used to determine if the interventions affected food insecurity, as well as motor, social/cognitive and language delays.

Results: At baseline, 2.6\% were categorized as "suspected developmental delay" and $14.2 \%$ were on "alert for development delay." Food insecurity, diarrhea and 
respiratory infections were lowered following the interventions. Through the "step-by-step" approach, caregivers in IC gained skills in gardening, conscious nutrition and parenting that reduced the risk of food insecurity [Adjusted Risk Ratio $=0.20$ (95\% Cl: 0.08-0.51)] and language delay [0.39 (0.19-0.82)] but not motor or social/cognitive delay. Use of a multiple micronutrient supplement decreased the risk of motor delay $[0.12(0.03-0.56)]$, but more pets were associated with higher risk of motor [3.24 (1.47-7.14)] and social/cognitive delay [2.72 (1.33-5.55)], and of food insecurity [1.73 (1.13-2.66)].

Conclusion: The combined interventions delivered by CHPs helped to mitigate the impact of adversity on food insecurity and language delay. Additional improvements may have been detected if the interventions had continued for a longer time. Our results indicate that control of infections and pets may be needed to achieve measurable results for motor and social/cognitive development. Continuous monitoring facilitated adjusting implementation strategies and achieving positive developmental outcomes.

Keywords: monitoring, learning system, infant development, diet diversity, food secuity, language development, caregiver-child interaction, home gardens

\section{INTRODUCTION}

The World Health Organization estimates that in any country about $10 \%$ of the population has some type of disability or developmental delay (1), and based on growth retardation and poverty measures, an estimated $43 \%$ of children under 5 are at risk of not reaching their development potential (2). Surveys of 35 low and middle-income countries have reported that $14.6 \%$ of children have low scores in the early development index associated with cognition, $26.2 \%$ have low socio-emotional scores, and $36.8 \%$ have both conditions (3). It is projected that children at risk of developmental delay due to growth problems and poverty will have a quarter of the average income of one adult per year, and that the cost of lack of action to the net domestic product can become twice as much as those countries that invest in health (4). Thus, the decline in growth retardation, the primary measure of chronic malnutrition (5), is considered a global priority, and a call has been made to investigate possible cost-effective and scalable interventions for the transition to the Sustainable Development Goals post-2015 (6). Current evidence on risk factors for developmental delay in early childhood in low-income areas includes a number of preventable factors that can alter the course of neurodevelopment including nutrition, infectious diseases and inflammation, caregiver insensitivity and chronic stress (7).

Food insecurity influences child development through its effects on nutrition and by producing stress in the family (8). Small children achieve satiety with cheap foods like sweetened

\footnotetext{
Abbreviations: CC, control communities; CHPs, community health promoters; CPR, rural population centers; IC, intervention communities; HCAZ, head circumference for age Z-scores; ICDP, International Child Development program; LAZ, length for age Z-scores; MINSA, Peruvian Ministry of Health; MMN, multiple micronutrients; PAHO, Pan-American Health Organization; UIGV, Inca Garcilaso de la Vega University; WAZ, weight for age Z-scores; WLZ, weight for length Z-scores.
}

liquids and junk food, but the total intake of macro and micronutrients may be insufficient for normal growth (8). Interventions with home and community gardens constitute an important strategy to improve food security, and particularly in the Andean region, provide the opportunity to grow traditional products with high nutritional value (9). Interventions that include creating home gardens and the consumption of traditional regional foods have shown improved food diversity in infants undergoing complementary feeding (10) for growth and achieving adequate weight and height (11).

Both protein energy malnutrition and/or infections produce not only growth retardation, but also structural and functional brain damage that presents as a delay in the development of cognitive functions and permanent cognitive damage (12). Among specific nutritional deficiencies, anemia as a manifestation of iron deficiency is one of the main causes of brain damage and delay in cognitive, behavioral and psychomotor development (13). However, nutrition-focused interventions have not always been successful. This is believed to be due to the inflammation caused by infections or environmental enteropathy, largely associated with the absence of clean drinking water or adequate sanitation and hygiene $(14,15)$. In fact, interventions that include water improvement, sanitation and hygiene have been shown to have a positive effect not only in the reduction of acute diarrheal disease, but also in respiratory infection, intestinal parasitism and other infectious diseases, with a final result of improvement in the anthropometry of children (16).

Recent research has demonstrated the importance of the caregiver-child relationship in child development, finding, for example, that harmonious, reciprocal interactions that reflect an emotional relationship evidenced by emotional and/or verbal sharing, improve cognitive and mental development and children's language (17). It is known that the practice of verbal and non-verbal attitudes by the caregiver to the 
child during early stages of child's development is able to modulate the expression of language systems (18). On the other hand, an inadequate caregiver-child interaction may result in eating disorders, physical under-development, decreased attention and cooperation, and an inability to learn and to develop adequate interpersonal relationships (19). Moreover, it has been documented that infants of caregivers who used positive parenting skills had greater increases in language production (20), and that characteristics of caregivers can influence the nutritional status of the child, even when controlling for the socio-economic status (21).

The first 1,000 days of life constitute an important window to improve health conditions in early childhood and in mothers to prevent the cycle of inter-generational delay (22). A recent analysis of strategies aimed at improving the development of children, shows that in order to achieve adequate development of children, multi-sectoral interventions are required in health, nutrition, education and child protection (23).

The goal of this project was to explore whether a multi-dimensional approach to early child development that emphasized home gardens, nutrition and improved caregiverchild interaction in a context of ongoing adaptation to local conditions would demonstrate results in a marginalized community in a relatively short 18 month time frame. The project was structured as both a field intervention for early child development and a longitudinal study to shape and describe the impact on health and development of children 03 years from "Centros Poblados Rurales" (CPRs) of Pachacámac (Peru), through participation of community health promoters (CHPs) and the local Ministry of Health. The Wawa Illari ("Wawa $=$ child, Illari $=$ resplendent" in Quechua) project consisted in the combination and ongoing adaptation of three interventions: (1) creation of community and home gardens, (2) workshops in conscious nutrition and meal preparation, and (3) improvement of the caregiver-child interaction, compared to the standard intervention.

\section{METHODS}

\section{Study Design}

This was a prospective, interventional, pre-post study that compared the occurrence of developmental delay in children aged $0-3$ years between intervention and non-intervention communities in an urban settlement area in Lima, Peru. We investigated whether the combination of community/home gardens, workshops in conscious nutrition and international child development program (ICDP) methodology would positively affect the growth and development of children 0-3 against the background of ongoing current Peruvian Ministry of Health (MINSA) protocols in both control and intervention communities. The intervention consisted of three activities introduced in sequence (Figure 1): home gardens, nutrition workshops focused on awareness of child needs "conscious nutrition," and "ICDP" workshops focused on caregiver-child interactions. Each of these interventions were intentionally adapted in response to challenges and feedback over the course of the study (Table 1). The children were monitored 3 times: at baseline, 8 , and 12 months.

\section{Context}

This study was conducted in urban settlements to the north and south of the district of Pachacámac, based on recommendation from nurses in the Pachacámac Public Health Center who identified these as the neediest communities in the region. This area, 59 kilometers south but within metropolitan Lima, features barren, rocky hills with scattered housing communities without paved roads. The valley floor has one main rutted dirt road, and multiple small farms known for strawberries. There were no large grocery stores or pharmacies, only small stores selling a limited range of foods. Most housing was precariously built of thin boards, and only one or two rooms. Some homes were made with bricks and plaster. There was no public water or sanitation system. Water was from wells stored in a large tank at the highest elevation in each community and delivered via plastic pipe to 50 gallon tanks at each family home. Community leaders were responsible for chlorinating the central tank water each month, but times and amounts of chlorine used were irregular. There was no public infrastructure for essential sanitation services or roads, though there were two public health clinics, two public preschools, one elementary school, one high school and several churches.

During 2018, the Ministry of Health (MINSA) conducted two campaigns to detect and treat anemia in both the control and intervention communities that overlapped with our nutrition and ICDP workshops. They also provided micronutrient supplements in the form of a sachet ( 1 dose): $12.5 \mathrm{mg}$ of elemental iron, $5 \mathrm{mg}$ of zinc, $160 \mu \mathrm{g}$ of folic acid, $300 \mu \mathrm{g}$ of vitamin A and $30 \mathrm{mg}$ of vitamin $\mathrm{C}$, to be administered daily for 1 year to children starting at 6 months of age (24).

\section{Community Selection, Sample Size Estimates, and Recruitment Procedures}

The study area was divided as CPRs of North and South, which were separated by an urban area that served as a natural border and prevented contact between control and intervention communities. The southern region was inhabited by recent migrants from rural areas of Peru whereas the northern region was home to families that had been relocated from settlements during social programs. Selection of communities was based on inclusion within regions served by the Manchay and San-Juan (South), and Las-Palmas (North) health centers. Randomly, the southern CPRs were chosen as the intervention zone (Pampachica, Manchay Bajo, Lote B, Manchay Alto, Curva Zapata, and San Juan), and the northern CPRs were chosen as the control (Casitas, Rinconada and San-Miguel).

Sample size estimates were based on a prevalence of developmental delay of $14.6 \%$ in $0-3$ year old children from low-middle income countries (7). Using OpenEpi software (25), we estimated that a sample size of 100 children in each of the control and intervention communities would be needed to detect with $95 \%$ confidence a decrease of 0.2 in the odds of developmental delay as defined by the Pan-American Health Organization (PAHO) (1).

Meetings were held with community leaders and families from the intervention and control areas to explain the project. Nursing professors of the Inca-Garcilaso-de-laVega University (UIGV) trained in technical and ethical 


\begin{tabular}{|c|c|c|c|c|c|c|c|c|c|c|c|c|c|c|c|c|c|c|}
\hline & \multicolumn{6}{|c|}{2017} & \multicolumn{12}{|c|}{2018} \\
\hline & Jul & Aug & Sep & Oct & Nov & Dec & Jan & Feb & Mar & $\mathrm{Apr}$ & May & Jun & $\mathrm{Jul}$ & Aug & Sep & Oct & Nov & Dec \\
\hline \multicolumn{19}{|l|}{$\begin{array}{l}\text { Training UIGV } \\
\text { professors for } \\
\text { recruitment }\end{array}$} \\
\hline \multicolumn{19}{|l|}{ Recruitment } \\
\hline \multicolumn{19}{|l|}{$\begin{array}{l}\text { Training MINSA } \\
\text { nurses (Conscious } \\
\text { Nutrition) } \\
\end{array}$} \\
\hline \multicolumn{19}{|l|}{ Baseline evaluation } \\
\hline \multicolumn{19}{|c|}{ Recruitment of CHPs } \\
\hline \multicolumn{19}{|c|}{$\begin{array}{l}\text { Training CHPs } \\
\text { (Gardens) }\end{array}$} \\
\hline \multicolumn{19}{|l|}{$\begin{array}{l}\text { Community and } \\
\text { Family Garden } \\
\text { Intervention }\end{array}$} \\
\hline \multicolumn{19}{|c|}{$\begin{array}{l}\text { Training CHPs } \\
\text { (Conscious Nutrition) }\end{array}$} \\
\hline \multicolumn{19}{|c|}{$\begin{array}{l}\text { Conscious Nutrition } \\
\text { Intervention }\end{array}$} \\
\hline \multicolumn{19}{|c|}{ Armed conflict in IC } \\
\hline \multicolumn{19}{|c|}{$\begin{array}{l}\text { Construction work in } \\
\text { Health Centers }\end{array}$} \\
\hline \multicolumn{19}{|c|}{ Mid Evaluation } \\
\hline \multicolumn{19}{|c|}{$\begin{array}{l}\text { Training } 14 \text { CHPs } \\
\text { ICDP (caregiver level) }\end{array}$} \\
\hline \multicolumn{19}{|c|}{$\begin{array}{l}\text { Training 8 CHPs } \\
\text { ICDP (facilitator } \\
\text { level) with weekly } \\
\text { follow-up and } \\
\text { supervision }\end{array}$} \\
\hline \multicolumn{19}{|l|}{ ICDP Intervention } \\
\hline Final evaluation & & & & & & & & & & & & & & & & & & \\
\hline
\end{tabular}

FIGURE 1 | Timeline for Wawa lllari project.

recruitment procedures accompanied by their students and guided by MINSA nurses then visited homes with at least one child 0-3 years of age, to explain the study using picture cards. MINSA nurses also recruited children during regular growth and follow-up in the Manchay and Las Palmas health centers.

The two inclusion criteria were at least one child aged $0-3$ years, and agreement of the caregiver to allow us to monitor the growth and development of their children in 3 evaluations distributed during the project duration and answer several questionnaires. In the case of the intervention communities, the caregivers also agreed to receive the proposed methodology, work in home gardens and attend training workshops. This was indicated by written informed consent. The exclusion criteria were chronic diseases or congenital malformations; no children had these conditions.

A total of 315 children were recruited, 157 from the control communities (CC) (71 boys and 86 girls), and 158 from the intervention communities (IC) (92 boys and 66 girls). At the end of the project, 127 children from the CC (58 boys, 69 girls) and 113 from the IC (65 boys, 48 girls) had completed at least two of three evaluations and were included for analysis.

\section{Intervention Methodologies}

During the course of the project, a number of challenges emerged which required adaptation to our original design. These are summarized in Table 1.

\section{"Step-By-Step" Learning System for Community Health Promoters (CHPs)}

The research team identified 15 people of the IC who were willing to be trained as CHPs in each of the intervention methodologies and carry these messages to designated households. Training was adapted from intense sessions to a more "step-by-step" process with smaller and more focused specific training (ASM) ${ }^{1}$ that was more effective for transfer the knowledge to the families, regularly reinforced by experts. Throughout the training, the importance of encouraging parents to have a conversation with the children whether during gardening, cooking, washing hands, brushing

\footnotetext{
${ }^{1}$ Contact information on "step-by-step” training: sofia.mazzini@gmail.com.
} 
TABLE 1 | Summary of adaptations to methodologies in response to specific field challenges.

Initial plan
Partnerships
- Experts in the methodology would train UIGV
nursing school professors who, with their
students, would recruit participants,
implement and evaluate the interventions as
part of the curriculum.

\section{Garden intervention}

- An agricultural engineer based in Lima was initially hired to lead planning and planting community gardens.

- Community gardens would be planted in each small community on public land.

- Families would pick-up from central locations seeds and small plants to start family gardens.

- Training of volunteer CHPs in garden methodology over continuous sessions in one intensive week.

\section{Conscious nutrition}

- Community workshops delivered directly to caregivers at a community kitchens

- Foods were to be purchased from a wholesale market, and distributed in small packages so CHPs could take them to the families

\section{First post-intervention evaluation}

- Evaluation of children 6 months after baseline, following the gardening and nutrition interventions
Field situation

- After the initial training and recruitment, the UIGV realized that logistics, security, contractual and technical difficulties did not allow them to continue the partnership.

- Intervention families were scattered within CPRs over $5 \mathrm{~km}$ in a steep terrain making access to community gardens difficult

- The agricultural engineer provided a program outline, budget and large donation of seeds from a local company, but the needed shift to a house-by-house methodology was not suitable for him.

- There was land available only in 2 communities

- Soil tests indicated no nitrogen in soil that was essentially ground rock, and families lacked transportation to obtain soil and other materials.

- There was no rain in the region, the soil was arid and the area had a high solar radiation factor.

- The intensive training was insufficient given the varied level of education (elementary school to high school), with one local organic gardener, and given that the un- or under-employed CHPs (14 female and one male) needed to have some payment and also to take care of their homes and children.

- There was only one community kitchen in one of the intervention communities, and it lacked the minimal criteria of water and hygiene.

- All mothers had difficulties meeting at specific times.

- The work load for wholesale purchase and preparation of individual packages was too high.

- A cold-chain was not available and most of beneficiaries including CHPs did not have a refrigerator.

- There were several weeks of armed violence over land issues in one intervention community. CHPs expressed their own and their community's feelings of fear, uncertainty and abandonment by local institutions. We were concerned about the health risks for CHPs to visit families.

- There was construction at the health clinics in Manchay and San Juan (IC) and Las Palmas' clinic (CC) was closed due to lack of water and energy supplies.

- Seven CHPs declined the temporary part-time employee status because they did not want to lose the free government health insurance.
Adaptations

- Our "local team" in Lima took on the implementation, coordination and logistics for the entire intervention.

- People from the intervention communities were hired and trained as CHPs to bring the methodology to families.

- Nurses of the local Pachacámac Health Network supported the research component of the study.

- Two community gardens were established but the focus shifted to individual family gardens

- A nurseryman hauled soil and compost for both community gardens. One of them required a fence, a protective mesh shade cloth and the installation of a water tank.

- Fertile soil and recycled wooden produce boxes lined with porous fabric were provided seeds and seedlings and compost tea.

- Motorcycle taxis were hired to help mothers get heavy and bulky elements home. The local team took materials to the homes of those who were absent.

- CHP's spent a full day at an organic educational farm run by retired agriculture professors to learn organic practices.

- Learning was spread out over time, and refocused to transfer specific simple messages and tasks each week, through a learning system "gota-a-gota" (step-by-step).

- The local organic gardener became our lead supervisor and educator for the on-going gardening workshops.

- CHPs received a financial incentive.

- CHP's received nutrition training from our team expert.

- Given acceptability, feasibility and accountability of the "step-by-step" system, we continued applying it for the nutrition intervention.

- CHPs were provided with one recipe/week, main ingredients and key messages about hygiene using printed material that was delivered directly to each family at their homes.

- One CHP had a small store in the community. The 'local team' coordinated with her the order and distribution of small packages for other CHPs and their respective families. Only non-perishable items were distributed.

- Educational workshops were temporarily halted for the safety of the team. Monitoring of the situation was done using Whatsapp communication with CHPs.

- The mid-evaluation was delayed by 2 months. Safety protocols were implemented. Trips and time spent in the field were restricted.

- A stress questionnaire was developed for assessing the impact of conflict on children.

- We provided a tent for evaluation of children in Manchay, and the San Juan health center also installed a tent. In las Palmas, the nurse made appointments to evaluate participants in a restricted schedule.

- Only 8 CHPs were hired as part-time employees. They received caregiver- and facilitator-level training and were remunerated based on the number of families they were able to visit. The other 7 CHPs received ICDP training but did not participate further. 
TABLE 1 | Continued

\begin{tabular}{|c|c|c|}
\hline Initial plan & Field situation & Adaptations \\
\hline $\begin{array}{l}\text { - Intensive training in ICDP methodology over } \\
3 \text { days }\end{array}$ & $\begin{array}{l}\text { Even though we provided two levels of training, } \\
\text { CHPs had difficulty recalling and transmitting } \\
\text { the contents. }\end{array}$ & $\begin{array}{l}\text { - We reinforced one ICDP guideline and one sensitization } \\
\text { principle each week. }\end{array}$ \\
\hline $\begin{array}{l}\text { - ICDP workshops and supporting material are } \\
\text { designed to train small groups of parents. }\end{array}$ & $\begin{array}{l}\text { - The communities lacked appropriate locations for } \\
\text { group gatherings and caregivers were unable to } \\
\text { attend workshops at specific times. The } \\
\text { challenge was to change the method of delivery } \\
\text { but not the content. }\end{array}$ & $\begin{array}{l}\text { - CHPs delivered the ICDP methodology directly to the } \\
\text { homes of participants using the "step-by-step" } \\
\text { learning system. }\end{array}$ \\
\hline
\end{tabular}

teeth, or playing was highlighted. CHPs also learned to encourage caregivers to name things from plants to food ingredients and to stimulate the child's sensory engagement in each activity. This approach was designed to allow CHPs to develop technical skills and to improve self-esteem and build a trust relationship with families.

The local team had weekly meetings with CHPs where they provided feedback about their experiences, shared difficulties and findings, and learned from each other. Little by little, CHPs took "ownership" for each methodology and its contents. Materials were also provided at these weekly meetings.

Each CHP was responsible for 7-11 families and each family had a weekly lesson in gardening, and later in nutrition, cooking and the ICDP methodology.

\section{Community and Home Gardens (On-Site Field Adaptations)}

Two community gardens were created, one in Manchay, and one in San Juan. They served as sites for training for CHPs who also maintained the gardens. They were available to any family who wished to make use of the gardens.

In addition, individual family gardens were promoted. A model workshop was held for the CHPs where they were provided with two wooden slat boxes, one for leafy greens (24" $\left.\times 18^{\prime \prime} \times 8^{\prime \prime}\right)$ and one for root crops $\left(24 " \times 18^{\prime \prime} \times 11^{\prime \prime}\right)$, each lined with polyester porous agricultural feed bags. Vegetables were selected based on both on the nutritional content and cultural acceptance with a focus on high iron content foods: parsley, spinach, cabbage, swiss chard, carrots, green onions as well as turnips, beets, and radishes that have edible leaves as well as roots. CHPs planted their own boxes to take home and learned how to provide instruction when they visited families.

Boxes, soil, compost, seeds for most crops as well as parsley and green onion plants were provided to 107 families. The initial garden intervention was provided over 12 visits, and then continued throughout the project. A specific task was covered each week to ensure ongoing learning and a successful harvest: planting, organic fertilizers, pest management, crop harvesting and seed harvesting for garden sustainability. At each visit, the caregiver signed a register to confirm participation and receipt of materials and the CHPs took photos of each garden. The last community intervention was planting a lemon, orange, apple or peach fruit tree at every child's home in the IC, as a way to promote environmental health, soil improvement and a future fruit supply. Fruit trees were also planted at the Niña Maria community garden and San Juan public pre-school community garden and the San Juan health center for long term community benefits. At each visit, CHPs continued to supervise gardens and to distribute seeds when required.

\section{Conscious Nutrition Intervention (On-Site Field Adaptations)}

The second phase of intervention was designed to increase the likelihood that infants receive nutrients known to improve infant development. CHPs received $12 \mathrm{~h}$ of training in conscious nutrition and cooking from our nutrition advisor that emphasized the preparation easy and tasty recipes using affordable local foods rich in macro- and micro-nutrients known to be essential for child development. The lessons emphasized connecting with the colors, smells and tastes of each food, and the importance of the parent's feelings while preparing food for the child (26). CHPs were provided with one recipe/week, main ingredients and key messages about hygiene using printed material.

Each CHP delivered the supplies and lessons directly to each family at the family home after practicing in their own home. They stressed the importance of a diet with a variety of flavors, colors and smells; in eating using the five senses; making meals a happy experience for a loving interaction between caregivers and children; the use of traditional and new local recipes to increase the variety in the diet; and to incorporate the families' garden produce. Recipes also included the mixture of multiple micronutrient (MMN) powder with foods, following MINSA guidelines (24). Children responded with pleasure to all the recipes which encouraged mothers to put them into practice. The follow up of every family visit was also done by asking for participants' signatures and taking pictures of prepared foods.

\section{Adaptation of International Child Development Program (ICDP)}

The International Child Development Program (ICDP) (27), our third aspect of the intervention, has two levels of training. For the first 'caregiver level,' the local team provided 6 training sessions of $3 \mathrm{~h}$ /week whereby CHPs practiced the ICDP methodology with their own children in order to internalize the process. For the second 'facilitator level', an additional 8, 2-h sessions focused on the 7 sensitization principles of the ICDP approach that promote "sensitization" rather than "teaching" in order to 
encourage caregivers to make positive changes. These sessions helped CHPs to facilitate parent-child interactions in a way that showed empathy toward parents and children through sharing of personal stories, putting themselves in the caregiver or child's place, demonstrations and role playing games, listening to caregivers and giving simple explanations. Through this process, CHPs understood the need to incorporate all the guidelines in each caregiver-child interaction given that they are mutually reinforcing. Eight CHPs participated in the facilitator training.

Eight ICDP workshops were provided at each home. They focused on the three ICDP forms of dialogue (emotionalexpressive, meaning oriented and regulative dialogues) and covered by 8 specific ICDP guidelines $(27,28)$. The emotionalexpressive form of dialogue comprises the first 4 guidelines: (1) show love and positive feelings to your child, (2) follow and adjust to your child's initiatives, (3) establish close communication, with or without words, and (4) praise and appreciate your child's efforts and achievements. The meaning oriented dialogue includes the next 3 guidelines: (5) establish shared focus and attention with your child, (6) provide meaning by naming and describing things and actions, and (7) expand on meaning by connecting, comparing and using creativity (songs, stories, painting etc.). The regulative dialogue contains the two parts of the last guideline: (8a) establish limits, norms and values, and (8b) guide your child's activity step by step toward a goal.

Caregivers learned to apply sensitization principles by sharing personal experiences, providing explanations and concrete examples, and facilitating role-games and direct interaction with children. Story books and didactic wooden toys were used. Though not part of the original ICDP material, they were helpful in promoting caregiver-child interactions during home visits.

\section{Monitoring of Children}

Children were assigned to one of three health centers for monitoring based on proximity to the home: San-Juan or Manchay for IC, and Las Palmas for CC, and were followed by MINSA nurses in charge of the Growth and Development program who received specialized training for the research. The main outcome was the development of children, evaluated through the PAHO growth and development scale (29) which is also the basis for Peruvian guidelines for the follow-up of children under five (30).

\section{Questionnaires}

In addition to a baseline questionnaire administered only at the beginning of the study, questionnaires on child feeding, food security, and health of the child were administered at 0,8 , and 12 months, and the stress questionnaire was administered at 8 and 12 months.

\section{Baseline}

The baseline evaluation included questions on the caregiver and home, including age, education, marital status of the parents, number of people living in the household and in the same room with the child, presence of pets and vermin at home (31) In addtion, data on the following PAHO risk factors for developmental delay (1) were recorded: presence of maternal anemia, hypertension, urinary tract infection and other complications during the pregnancy of the participant child, weeks of gestation, infant birthweight, development of neonatal jaundice, exposure to wood or cigarette smoke at home, and frequent consumption of alcohol by someone in the household.

\section{Child feeding}

Caregivers were asked if the infant was currently receiving breastmilk (0: no, 1: yes). For those who were taking food, a locally adapted food frequency questionnaire was applied using a list of foods that were common in the region (32) (Supplementary Table 1). The nurse asked whether the child ate each item as part of their usual diet. Each item was given a score of one and variety of foods eaten by children was defined as the number of foods used to feed children in each evaluation period. Caregivers also indicated whether or not their child was receiving MMN supplements.

\section{Food insecurity}

Scores (0-3) were assigned to a positive response to the following questions that referred to the past 6 months for the household. Did you worry about having enough food due to lack of resources (0: no, 1: yes)? Was there a limitation in the types of foods that were consumed due to lack of resources (0: no, 2: yes)? Was there a lack of food at home due to lack of resources (0: no, 3: yes)? Was there a lack of appropriate foods for the child due to lack of resources (0: no, 3: yes)? The highest individual score was used to reflect the degree of food insecurity as follows: (0) no food insecurity, (1) mild food insecurity, (2) moderate food insecurity, and (3) severe food insecurity (33).

\section{Health assessment}

Nurses asked the caregiver about the presence and frequency of diarrhea ( $\geq 3$ liquid stools/d) and respiratory infections (syndrome of cough and fever of any severity) following PAHO Integrated Management of Childhood Illness (IMCI) strategy (29), and number of visits to the doctor due to illness (including hospitalizations) in the last month. Children were considered to have persistent diarrhea or respiratory infections if the number of episodes recorded in the second and third evaluations were found to be equal or higher to that from the previous evaluation(s).

\section{Stress}

A novel stress assessment questionnaire was validated following a period of armed conflict that affected some CPRs of the intervention region at the end of conscious nutrition workshops. Nurses asked if, in the past 3 months, the caregiver or the family had lived in stressful situations. If the answer was "yes," child stress was evaluated by asking caregivers if the child ate less than usual, slept less than usual, woke up scared, cried more frequently, looked sad, showed less desire to play, or was unable to play outside for safety reasons. A score of 1 was given to any affirmative answer, and the cumulative score (range 0-7) was calculated. For evaluating caregiver stress, nurses also asked if the stressful situation had affected caregiver's ability to get food for the child, if the caregiver easily got mad at the child, and if the caregiver was less willing to play with the child. Similarly, scores for positive answers ranged from 0 to 4 . 


\section{Overall qualitative assessment of the intervention}

At 8 and 12 months, caregivers were asked whether they incorporated their garden produce into the family meals, and whether they used nutrition and caregiver-child lessons and skills in daily life.

\section{Anthropometry}

Child weight, length/height and head circumference were measured three times $(0,8$, and 12 months) following WHO standards (34). For infants, nurses used the Seca $354^{\circledR}$ digital scale for babies, the Seca $210^{\circledR}$ mobile measuring mat for baby and toddler, and the Seca $201^{\circledR}$ circumference measuring tape. For children 1-4 years, a Seca $769^{\circledR}$ Wireless Eye-Level Digital Scale with Height Rod was used. Z-scores of weight-forage (WAZ), length-for-age (LAZ), weight-for-length (WLZ) and head-circumference-for-age (HCAZ) were calculated using the STATA 14 least mean squares method applied to WHO reference data (35).

\section{Intestinal Parasites and Anemia}

Stool samples, collected from children at the first and second evaluation periods, were examined for intestinal parasites using a sedimentation technique and for pinworms using the Graham's scotch tape test for pinworms. Heel or finger-prick blood samples were collected by nurses at the three evaluation periods and assayed hemoglobin (hemoglobinometer HemoCue Hb 301 Auto $\left.^{\circledR}\right)$. Anemia was defined as hemoglobin $<11 \mathrm{~g} / \mathrm{dL}(36)$.

\section{Evaluation of Caregiver-Child Interaction}

The ICDP program is usually evaluated with the help of pre- and post-intervention video $(27,28)$ which was not possible in our context due to technical constraints and ethical considerations. Instead, we used two approaches to evaluate caregiver-child interactions.

For an objective evaluation of ICDP workshops, we developed and validated a novel checklist based on gestures or expressions that reflected ICDP guidelines (27). MINSA nurses were trained in 3 sessions of $6 \mathrm{~h}$ to use this checklist when observing caregiver attitudes that reflected ICDP guidelines. In the last two evaluation periods, caregivers in both IC and CC were given the opportunity to interact with the child (diaper change, breastfeed, giving food and/or play) while the nurse, at a distance, observed the caregiver's application of the 8 ICDP guidelines (Supplementary Table 2). Nurses classified the interaction as (0) if the gesture/attitude was not present, (1) if observed occasionally, and (2) if observed frequently. A score adding nurse's observations was created for each guideline.

During the last visit to the families, a subjective evaluation of ICDP workshops was completed by IC caregivers. They used a Likert scale to provide a self-assessment of the application of the 8 guides. CHPs asked caregivers whether they would currently rate their attitudes about each ICDP guide as very low, low, medium, a lot, or very much. They asked the same question about their attitudes prior to the ICDP workshops. The CHPs provided a visual representation to highlight areas of improvement (Supplementary Figure 1).

\section{Child Development Evaluation}

Child development was evaluated using the PAHO standards based on the guidelines for Integrated Management of Childhood Illness (IMCI) (1). This instrument is widely used in Latin America to monitor child development as part of the routine health care. The instrument assesses reflexes, attitudes and skills based on age-specific milestones ( $<2$ months, $\geq 2$ months and $\leq 2$ years, $>2$ and $\leq 6$ years) (Supplementary Table 2) (29). Using PAHO guidelines, child development was classified into four general categories: "normal" if the child displayed all the reflexes/positions/skills corresponding to her or his age group and there were no risk factors; "normal development with risk factors" if the child displayed all the reflexes/positions/skills corresponding to her or his age group, but there were one or more risk factors; "developmental alert" if the child did not display one or more of the reflexes/positions/skills corresponding to the his or her age group; and "suspected developmental delay" if the child did not display one or more of the reflexes/positions/skills corresponding to the previous age group, or had a head circumference $<2 \mathrm{SD}$ or $>2 \mathrm{SD}$, or presented three or more phenotypic alterations (29). In addition, the medical research team categorized PAHO milestones as indicators of motor, social/cognitive and language subgroups (Supplementary Table 2). Child's motor, social/cognitive and language development were considered as delayed if respective age-specific milestones were not observed across evaluations, or if milestones were absent in an evaluation when previously they were present.

\section{Statistical Analyses}

Questionnaires completed by nurses were digitally transferred weekly. Database verification by a second digitizer was made at the end of each evaluation. STATA/IC 16.1 for Mac (StataCorp, TX, USA) was used for analyses.

At baseline, child, caregiver and household characteristics, as well as risk factors for developmental delay were compared between CC and IC using $\mathrm{Chi}^{2}$ or Fisher's exact test for frequencies, Kruskall-Wallis test for ages and Student's $t$-test for birth weights.

To determine differences in categorical variables across evaluation points separately for CC and IC, Cochran tests for equality of proportions in matched samples were performed. $\mathrm{Chi}^{2}$ or Fisher's exact test were used to compare CC and IC at each evaluation. The following categorical outcomes were evaluated: frequency of different degrees of food insecurity, presence of intestinal parasites, presence of anemia, presence of reported stress signs in children, proportion of children in each development category and proportion of children not achieving developmental milestones for motor, social/cognitive and language development.

Variables were compared across time-points using KruskalWallis tests (episodes of diarrheal and respiratory infections, number of visits to the doctor due to illness in the last month, foods taken by children, child stress scores, and caregiver-child interaction scores), and one-way ANOVA (anthropometry Zscores and hemoglobin, g/dL). To assess differences between IC and CC, Kruskal-Wallis and Student's $t$-test were used. In 
order to determine whether an outbreak of violence within the IC region influenced child stress, the participants from IC communities were subdivided into those with or without violence and compared with those in the CC communities. The equality of stress scores at 8 and 12 months and of caregiver application of ICDP guidelines were tested by using the Wilcoxon matched-pairs signed-rank test. Kruskal Wallis was used to assess difference between IC and CC at 8 and 12 months.

We explored associations of food insecurity, motor, social/cognitive or language delays as dependent variables using stepwise multiple logistic regression models. Our independent variables were: received the combined intervention (0: CC, 1: IC), gender (1: boy, 2: girl), age at final evaluation (months), number of pets, number of vermin in the home, maternal education (years), paternal education (years), number of people sharing the bedroom with the child, breastfeeding (0: no; 1 : yes), number of episodes of diarrhea in the last month, number of episodes of respiratory infection in the last month, taking micronutrients (0: no, 1: yes), hemoglobin (g/dL) and child stress scale (0-7). The stepwise process took out variables with $p>0.15$. Then, adjusted risk ratios were calculated using the post-estimation "adjrr" command in STATA, which adjusts for covariates and uses the Delta method to calculate confidence intervals (37). Missing data were not imputed and complete case analyses were performed. Final models were assessed for collinearity (variance inflation factor $<10$ ) and stability of coefficients (condition number < 30).

Finally, to assess the specific impact of ICDP methodology on language development we ran logistic regression models for language delay and the score of caregivers' application of each ICDP guideline as observed by nurses. Risk ratios were adjusted for receiving the intervention.

\section{Ethical Aspects}

The study received ethical approval from the National Institute of Child Health (registration OEAIDE-029972017) and from the Research Ethics Board at McGill University (REB File \# 144-0817).

\section{RESULTS}

\section{Baseline Characteristics}

Characteristics of children, their parents, their homes, as well as risk factors for developmental delay are presented (Table 2) for 127 children from the CC and 113 from the IC who had baseline data and data from at least one follow-up evaluation. Children of CC and IC did not differ by age or sex (Supplementary Figure 2), birthweight or age of the parents. A lower proportion of mothers in the IC breastfed their children. In both IC and CC, most women $(84.4 \%)$ spent all day with their children, but most fathers $(84.8 \%)$ spent $\leq 2$ days/week. In the CC the mothers had more years of education but higher frequency of unstable unions than in IC; the CC also had fewer people sleeping in the same room as the child, fewer families with dogs or cats, but the presence of mosquitoes and rodents in the house was more frequent. Mothers of the IC reported hypertension during the pregnancy of the participating child more often than the mothers of the CC. Other
TABLE 2 | Characteristics of children, caregivers and households at the baseline evaluation in control $(n=125-127)$ and intervention $(n=97-113)$ communities.

Control Intervention $p$-value

\section{Infant characteristics}

Gender

Boys

Girls

Age (months), median (min-max)

Breastfeeding $^{\text {a }}$

Exclusive

Mixed

None

Birthweight (g), mean \pm SD

Parent characteristics

Maternal marital status

Single mother

Unstable union

Stable union

Mother's age (years), medium (min-max)

Mother finished secondary school, \%

Father's age (years), median (min-max)

Father finished secondary school

\section{Household characteristics}

$>5$ people in household

$\begin{array}{ll}45.7 \% & 57.5 \% \\ 59.3 \% & 42.5 \%\end{array}$

$14(1-37) \quad 14(0-41)$

0.07

$\begin{array}{lll}81.1 \% & 67.5 \% & \mathbf{0 . 0 2 8}\end{array}$

$17.3 \% \quad 24.7 \%$

$1.6 \% \quad 7.8 \%$

$3,369 \pm 4533,322 \pm 543$

0.24$$
\geq 3
$$

\section{Dog}

Cat

Other

Vermin

Flies

Mosquitoes

Cockroaches

Rodents

Food insecurity

None

Mild ${ }^{\mathrm{b}}$

Moderate ${ }^{c}$

Severe $^{d}$

\begin{tabular}{|c|c|c|}
\hline $0.0 \%$ & $3.7 \%$ & 0.001 \\
\hline $8.7 \%$ & $0.9 \%$ & \\
\hline $91.3 \%$ & $95.4 \%$ & \\
\hline $29(17-46)$ & $29(16-50)$ & 0.20 \\
\hline $76.3 \%$ & $61.5 \%$ & 0.013 \\
\hline $32(18-58)$ & 32 (19-67) & 0.74 \\
\hline $88.0 \%$ & $76.0 \%$ & 0.017 \\
\hline $29.1 \%$ & $25.5 \%$ & 0.53 \\
\hline $12.7 \%$ & $48.6 \%$ & $<0.0001$ \\
\hline $37.8 \%$ & $58.7 \%$ & 0.001 \\
\hline $26.0 \%$ & $39.4 \%$ & 0.027 \\
\hline $2.3 \%$ & $1.8 \%$ & 0.57 \\
\hline $62.2 \%$ & $73.4 \%$ & 0.07 \\
\hline $63.8 \%$ & $42.2 \%$ & 0.001 \\
\hline $38.6 \%$ & $27.5 \%$ & 0.07 \\
\hline $44.9 \%$ & $29.4 \%$ & 0.014 \\
\hline $32.3 \%$ & $44.9 \%$ & $<0.0001$ \\
\hline $2.4 \%$ & $5.6 \%$ & \\
\hline $60.6 \%$ & $14.9 \%$ & \\
\hline $4.7 \%$ & $34.6 \%$ & \\
\hline
\end{tabular}

PAHO's known risk factors for developmental delay
Anemia in pregnancy

Hypertension in pregnancy

Urinary tract infection in pregnancy

Other complications of pregnancy

Preterm birth ( $<37$ weeks)

Low birthweight $(<2,500 \mathrm{~g})$

Neonatal jaundice

Exposure to smoke (firewood or cigarette)

Presence of someone with alcohol

problems at home ${ }^{\mathrm{e}}$

$\begin{array}{ccc}29.1 \% & 38.1 \% & 0.15 \\ 8.7 \% & 20.6 \% & \mathbf{0 . 0 1 0} \\ 57.5 \% & 52.6 \% & 0.46 \\ 13.4 \% & 17.4 \% & 0.39 \\ 2.4 \% & 6.4 \% & 0.12 \\ 3.2 \% & 7.5 \% & 0.12 \\ 19.8 \% & 27.1 \% & 0.19 \\ 16.5 \% & 25 \% & 0.11 \\ 39.4 \% & 28.2 \% & 0.07\end{array}$

${ }^{a} n=77$ in control community.

${ }^{b}$ Mild food insecurity: the caregiver is worried about not having enough money to buy food. ${ }^{c}$ Moderate food insecurity: Food quality is compromised due to lack of resources.

${ }^{d}$ Severe food insecurity: Lack of food at home or not sufficient food for the child due to lack of resources.

${ }^{e}$ Alcohol problems refer to frequent, non-occasional intake of alcohol, or heavy intake of alcohol until drunkenness. Bold numbers indicate significant differences at $p<0.05$. 


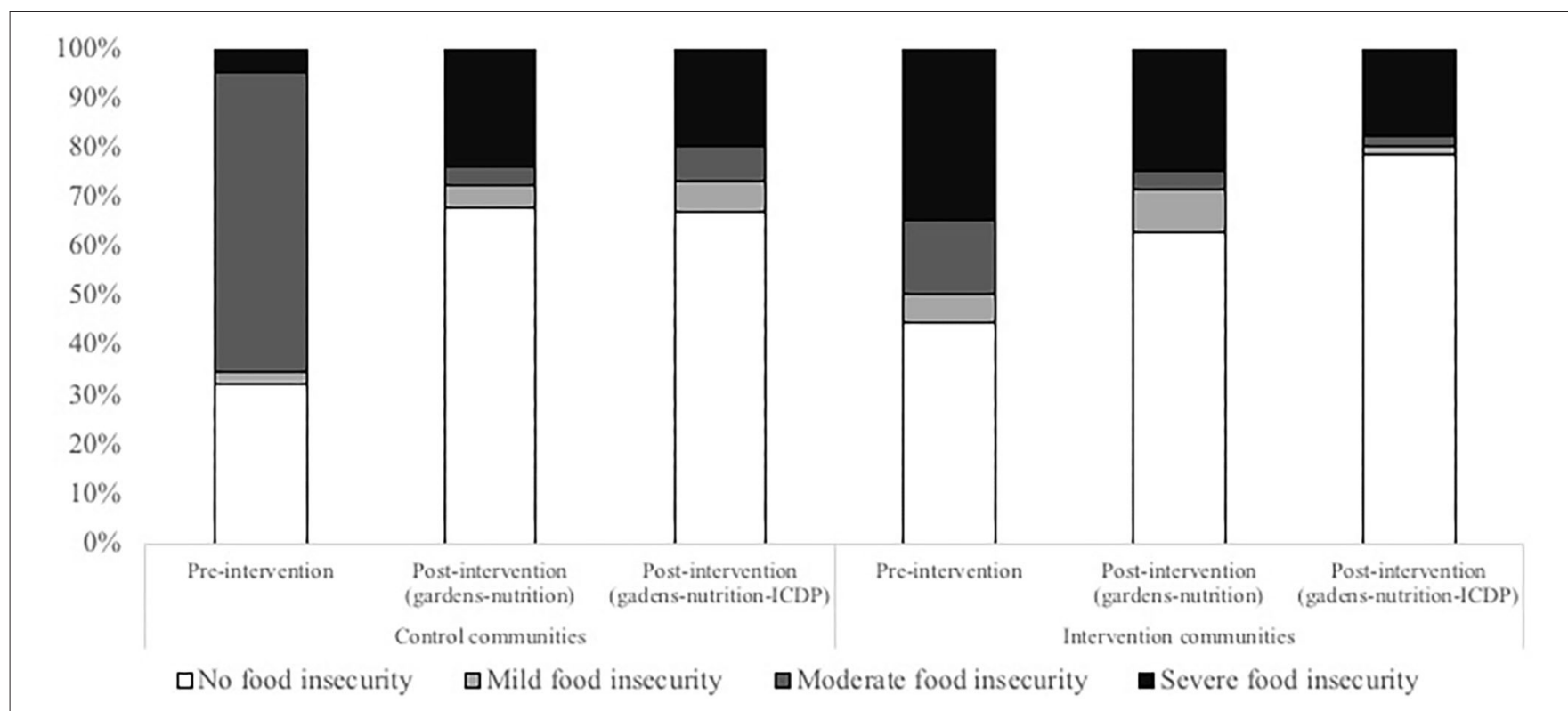

FIGURE 2 | Percentages of food insecurity (no food insecurity, mild, moderate and severe food insecurity) at three time-points in control and intervention communities.

PAHO risk factors for developmental delay did not differ between CC and IC (Table 2).

\section{Impact of the Interventions on Nutrition and Health \\ Food Insecurity and Variety of Foods Eaten by Children}

At baseline, moderate food insecurity was more frequent in the CC, but the IC had a higher percentage of severe food insecurity. The level of food insecurity did not differ between CC and IC at 8 or 12 months. However, within the IC, food security improved with a higher percentage of households reporting no food insecurity in the IC compared with the CC in the last evaluation (IC: $75.2 \%$, CC: $59.1 \%, p=0.017$ ) and a decrease in severe food security over time $(32.7-16.8 \%, p<0.0001)$ (Figure 2).

At baseline, children in CC ate a greater variety of foods compared with IC (average of 21 vs. 14 items, respectively, $p<$ $0.001)$. Although the difference remained across evaluations, the diversity of foods consumed by children increased more than 2fold over the study in both CC and IC (Supplementary Figure 3).

\section{Reported Frequency of Visits to the Doctor Due to Illness, Diarrhea and Respiratory Infection Episodes in the Last Month}

During the pre-intervention evaluation, caregivers of children in the IC reported a higher frequency of visits to the doctor due to illness (Supplementary Figure 4A), diarrheal (Supplementary Figure 4B) and respiratory disease (Supplementary Figure 4C) in the last month when compared to the CC (all $p=0.0001$ ). The number of visits to the doctor and episodes of diarrhea and respiratory infections in the IC declined at 8 and 12 months $(p=0.0001)$.
Intake of Multiple Micronutrients, Hemoglobin Concentrations and Presence of Anemia

Mothers in the CC reported giving MINSA-delivered MMN powder to children more often than in the IC. The number of children in the IC receiving MMN powder significantly increased during the course of the project (Table 3 ) but did not reach the proportion of the CC.

Although children in the CC had higher hemoglobin concentrations than those from IC in post-intervention assessments, we observed an increase in hemoglobin concentrations and decreased percentages of anemia in both IC and CC throughout evaluations (Table 3).

The prevalence of nematode infections (Enterobius vermicularis, Strongyloides stercoralis and Hymenolepis nana) was very low, but higher at baseline in the IC than CC (14.7 vs. $4.7 \%$ respectively, $p=0.022$ ). On the other hand, over $30 \%$ of children had one or more protozoan parasite, most commonly Giardia lamblia. Other protozoa found in the population included Blastocystis hominis, Chilomastix mesnili, Endolimax nana, Cryptosporidium parvum, Iodamoeba butschlii and Entamoeba coli. Even though diagnosis and referral for treatment of intestinal parasites occurred through MINSA in both control and intervention communities, the prevalence of Giardia at the 8 month evaluation had increased in the intervention community (4.4 to $25.6 \%, p<0.0001$ ).

\section{Anthropometry}

In general, children from $\mathrm{CC}$ and IC were within the normal range for weight, with very low prevalence of $\mathrm{WAZ}<-2 \mathrm{SD}$ (Figure 3A) and no children with WLZ $<-2$ SD (Figure 3B). LAZ $<-2$ SD was found in $4 \%$ of CC children and $9 \%$ of IC children at baseline (Figure 3C), and at 8 and 12 months the LAZ was lower in IC than CC children (Table 3). Abnormal head 
TABLE 3 | Health characteristics of children from control communities (CC) and intervention communities (IC) at baseline, at 8 months post-intervention (gardens-nutrition), and at 12 month post-intervention (gardens-nutrition-ICDP) ${ }^{1,2}$.

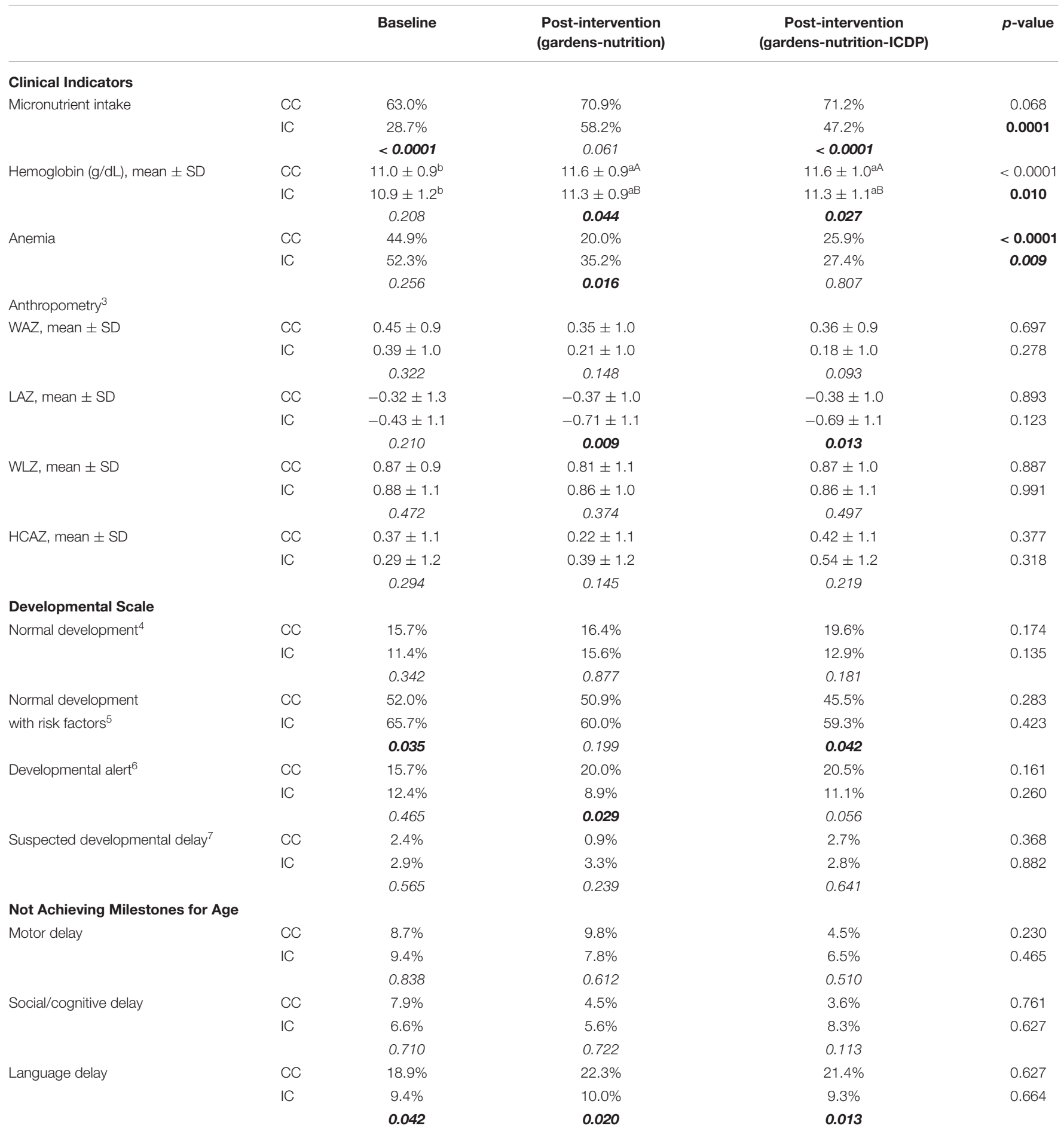

\footnotetext{
${ }^{1}$ Sample sizes: Baseline: $C C=127 ; I C=105-112 ; 8$ months: $C C=110 ; I C=90-93 ; 12$ months: $C C=102-112 ; I C=106-108$.

${ }^{2}$ Percentages were compared by Chi ${ }^{2}$ or Fisher's exact test. Means were compared across time by one-way ANOVA over three times or between IC and CC by Student's T-test. Different lower case superscripts represent significant differences over time; different upper case superscripts represent differences between CC and IC.

${ }^{3}$ WAZ, Weight for age Z-scores; LAZ, length for age Z-scores; WLZ, weight for length Z-scores; HCAZ, head circumference for age Z-scores.

${ }^{4}$ Normal development: child displays all reflexes/positions/skills corresponding to age group and no risk factors.

${ }^{5}$ Normal development with risk factors: child displays all reflexes/positions/skills corresponding to age group, but one or more risk factors.

${ }^{6}$ Developmental alert: child does not display one or more reflexes/positions/skills corresponding to age group.

${ }^{7}$ Suspected developmental delay: child does not display one or more reflexes/positions/skills corresponding to previous age group, or has $H C A Z<2 S D$ or $>2 S D$, or has three or more phenotypic alterations. Bold $p$ values indicate significant difference at $p<0.05$, and Italics denote comparisons between Control and Intervention Communities during the same evaluation point.
} 


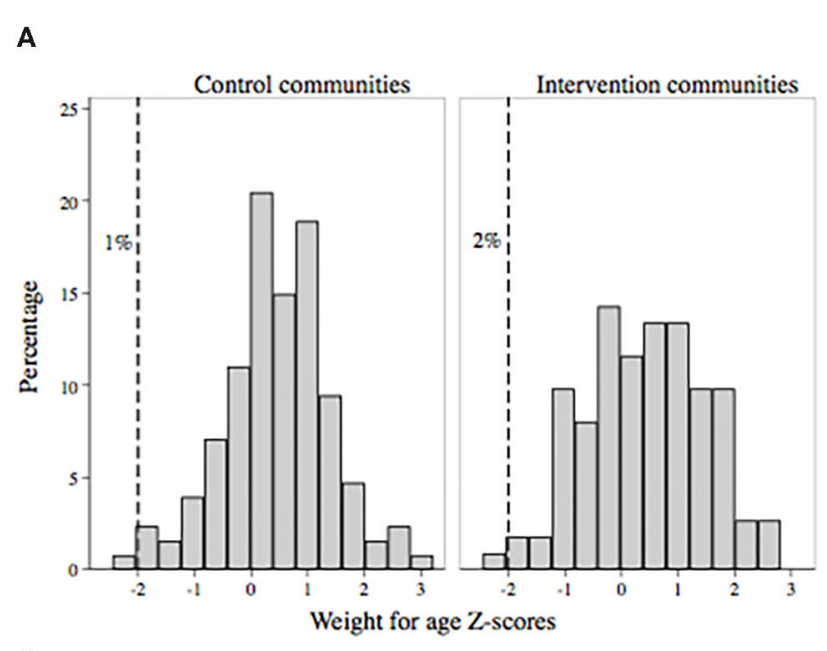

C

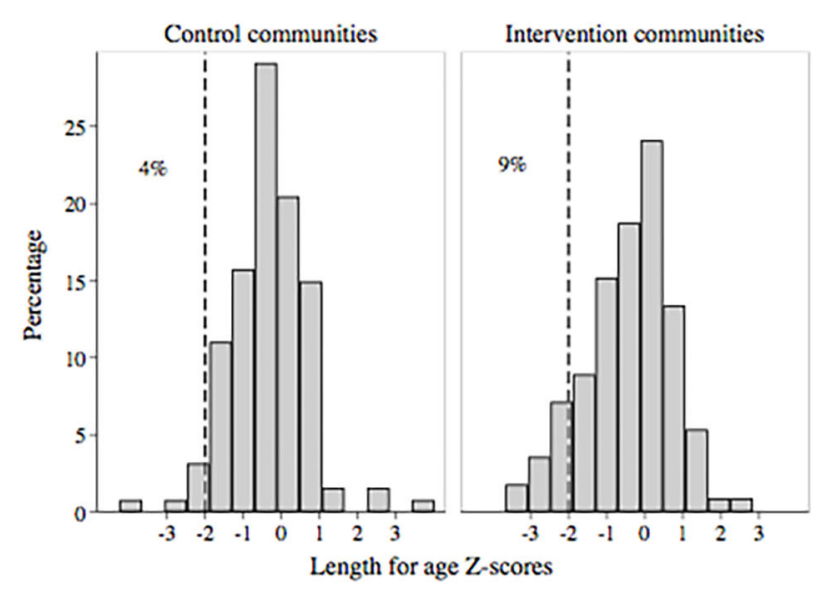

B
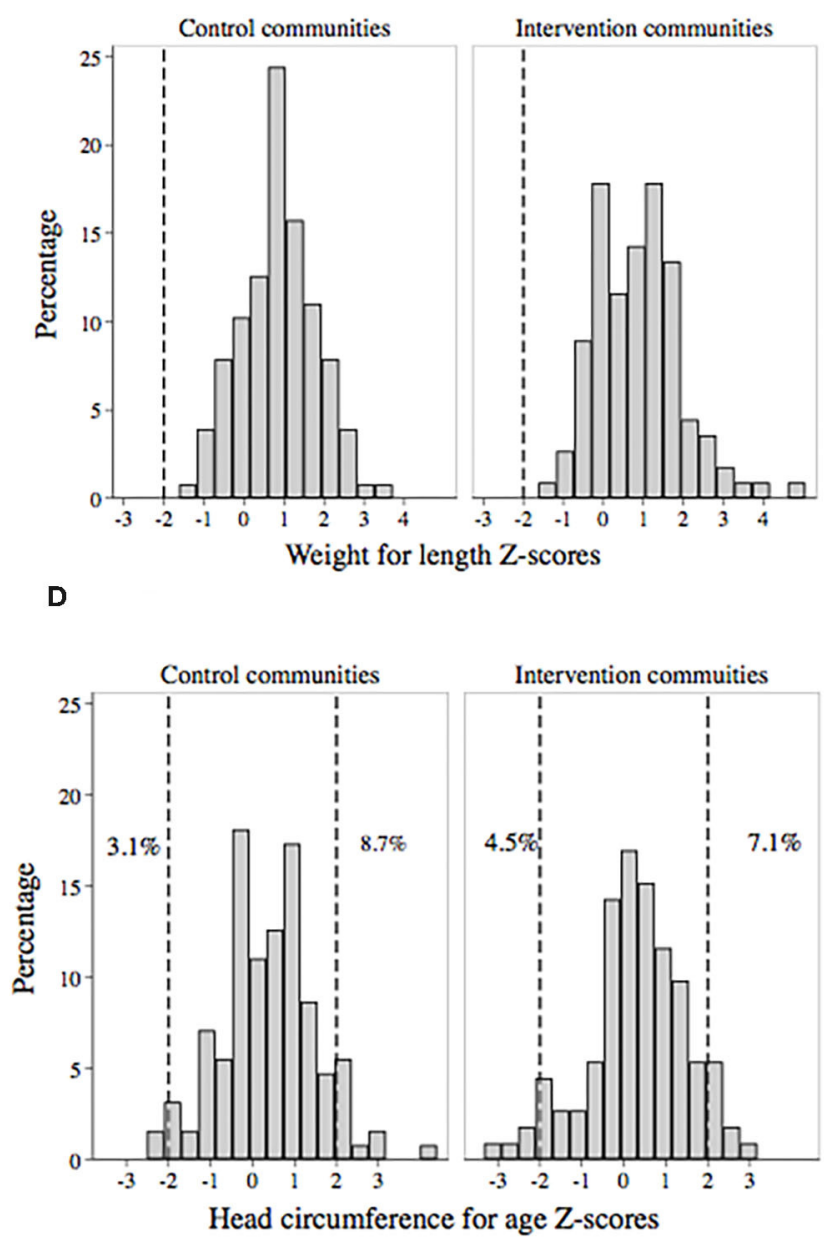

FIGURE 3 | Histograms of anthropometric measurements (Z-scores) in children 0-3 years from the control and intervention communities: (A) weight for age, (B) weight for length, (C) length for age, (D) head circumference for age at baseline evaluation.

circumferences HCAZ $(<-2$ or $>2$ SD) were present in $11.8 \%$ of children from the CC, and in $11.6 \%$ of children from the IC (Figure 3D).

\section{Impact of Interventions on Child Development}

When classifying children according to PAHO developmental scale, a higher proportion of children from the IC were categorized as "normal development with risk factors" at baseline and at 12 months (Table 3). At 8 months, after the intervention with gardens and nutrition but before the ICDP intervention began, the proportion classified as "developmental alert" was lower in the IC compared with the CC. There was no significant difference in the proportion of any of the developmental groups within communities over time.

When comparing achievement of developmental milestones, language delay for age was observed less frequently in children from the IC than $\mathrm{CC}$ at all time-points, but the percentage of children with language delay did not significantly differ over time. No differences were observed across evaluation periods or between CC and IC with regard to adequate motor development and social/cognitive development.

\section{Child and Caregiver Stress}

Due to the wave of violence in some of our intervention communities, we compared the presence and scores of stress in children and caregivers across evaluations and among participants in IC with and without violence and in CC communities. At 8 months, higher child and caregiver stress scores $(p=0.030$ and 0.001 , respectively) were observed in the IC communities with violence compared with non-affected communities. At 12 months, both child and caregiver stress scores were lower in the affected community ( $p=0.026$ and 0.049 , respectively) than at 8 months. Unexpectedly, at 12 months, both child and 
caregiver stress were highest in the CC $(p=0.028$ and 0.003 , respectively).

\section{Caregiver-Child Interaction}

The subjective caregiver evaluation of their own application of ICDP guides showed that all IC parents felt they had improved their skills and qualities as caregivers.

The objective assessment by nurses is shown in Table 4. Previous to the ICDP intervention, CC caregivers were better at following the child's lead (Guideline 2), verbal and non-verbal communication (Guideline 3), and helping the child to focus his/her attention and share experiences (Guideline 5), whereas IC caregivers were better at praising what the child manages to do (Guideline 4), helping the child to make sense of his/her world (Guideline 6), widen his/her experience (Guideline 7), and to learn rules, limits and values (Guideline 8a). After the ICDP intervention, caregivers in both IC and CC showed improvement in all guidelines, but caregivers receiving the ICDP intervention had higher scores than CC caregivers in Guidelines 1 (showing love, $p=0.015), 4,(p=0.0001), 6,(p=0.0001), 7(p=0.0001)$, $8 \mathrm{a}(p=0.0001)$ and $8 \mathrm{~b}$ (accompanying the child to learn step by step, $p=0.012$ ). At 12 months, IC caregivers had reached the level of CC caregivers in those guidelines that had been lower at 8 months.

\section{Multiple Regression Analyses for the Persistence or Worsening of Food Insecurity}

A multiple logistic regression analysis showed that after controlling for multiple confounders, receiving the intervention reduced the risk of worsened/persistent food insecurity at 12 months. On the other hand, a higher child stress score and more pets in the home increased the risk of worsened/persistent food insecurity (Table 5).

\section{Multiple Regression Analyses for Motor, Social/Cognitive, and Language Delay}

Of the possible parental, environmental, biological and stress factors that could have affected child development, only a few variables were significantly associated with developmental indicators.

Receiving the intervention package was not associated with an altered risk of motor or social/cognitive delay, but receiving MMN (which was included in recipes during nutritional workshops) decreased the risk of motor delay (Table 6A). A higher number of pets at home was associated with increased risk of both motor (Table 6A) and social/cognitive delay (Table 6B), and children having a higher stress score had a trend to a higher risk of motor and social/cognitive delay. Receiving the intervention was associated with $60 \%$ decreased risk of language delay (Table 6C) and children with higher number of diarrheal episodes had a borderline increased risk of language delay (Table 6C). The predicted probability of language delay when receiving or not the intervention at different age groups is shown in Figure 4.

In order to further evaluate the impact of ICDP methodology on language development, we ran multiple logistic regression models for language delay and the application of each ICDP
TABLE 4 | Scores reflecting caregiver interactions with their child ${ }^{a}$, based on observations by nurses of specific behaviors for each ICDP guideline ${ }^{\text {b. }}$ Scores were compared between 8 and 12 months using the Wilcoxon matched-pairs signed-rank test, and between intervention communities (IC) and control communities (CC) using Kruskal Wallis test.

\begin{tabular}{|c|c|c|c|c|}
\hline & Community & $\begin{array}{l}\text { ty Post-intervention } \\
\text { (gardens-nutrition) } \\
\text { at } 8 \text { months }\end{array}$ & $\begin{array}{c}\text { Post-intervention } \\
\text { (gardens-nutrition-ICDP) } \\
\text { at } 12 \text { months }\end{array}$ & $p$ \\
\hline \multirow[t]{3}{*}{ Guideline 1} & CC & $2.8 \pm 1.3$ & $4.8 \pm 1.6$ & $<0.0001$ \\
\hline & IC & $2.5 \pm 2.2$ & $5.4 \pm 2.3$ & $<0.0001$ \\
\hline & $p$ & 0.131 & 0.015 & \\
\hline \multirow[t]{3}{*}{ Guideline 2} & CC & $2.3 \pm 1.1$ & $3.4 \pm 1.2$ & $<0.0001$ \\
\hline & IC & $1.6 \pm 1.5$ & $3.6 \pm 1.9$ & $<0.0001$ \\
\hline & $p$ & 0.0001 & 0.788 & \\
\hline \multirow[t]{3}{*}{ Guideline 3} & CC & $4.1 \pm 1.6$ & $6.3 \pm 2.2$ & $<0.0001$ \\
\hline & IC & $3.4 \pm 2.8$ & $6.5 \pm 3.2$ & $<0.0001$ \\
\hline & $p$ & 0.0008 & 0.383 & \\
\hline \multirow[t]{3}{*}{ Guideline 4} & CC & $0.7 \pm 0.9$ & $1.8 \pm 0.9$ & $<0.0001$ \\
\hline & IC & $1.2 \pm 1.2$ & $2.5 \pm 1.3$ & $<0.0001$ \\
\hline & $p$ & 0.011 & 0.0001 & \\
\hline \multirow[t]{3}{*}{ Guideline 5} & CC & $1.3 \pm 0.9$ & $2.1 \pm 0.8$ & $<0.0001$ \\
\hline & IC & $0.8 \pm 1.0$ & $2.1 \pm 1.4$ & $<0.0001$ \\
\hline & $p$ & 0.0002 & 0.671 & \\
\hline \multirow[t]{3}{*}{ Guideline 6} & CC & $0.6 \pm 0.6$ & $1.5 \pm 1.2$ & $<0.0001$ \\
\hline & IC & $1.4 \pm 1.6$ & $3.1 \pm 2.0$ & $<0.0001$ \\
\hline & $p$ & 0.0005 & 0.0001 & \\
\hline \multirow[t]{3}{*}{ Guideline 7} & CC & $0.2 \pm 0.7$ & $1.7 \pm 1.6$ & $<0.0001$ \\
\hline & IC & $1.3 \pm 1.9$ & $3.6 \pm 2.6$ & $<0.0001$ \\
\hline & $p$ & 0.0001 & 0.0001 & \\
\hline \multirow[t]{3}{*}{ Guideline 8a } & CC & $0.4 \pm 0.9$ & $2.2 \pm 1.2$ & $<0.0001$ \\
\hline & IC & $1.3 \pm 1.3$ & $3.2 \pm 2.0$ & $<0.0001$ \\
\hline & $p$ & 0.0001 & 0.0001 & \\
\hline \multirow[t]{3}{*}{ Guideline 8b } & $\mathrm{CC}$ & $0.9 \pm 1.5$ & $3.5 \pm 1.7$ & $<0.0001$ \\
\hline & IC & $1.3 \pm 1.6$ & $4.3 \pm 2.6$ & $<0.0001$ \\
\hline & $p$ & 0.060 & 0.012 & \\
\hline
\end{tabular}

${ }^{a}$ For each behavior associated with a single guideline (see Table 7), nurses classified the caregiver-child interaction as (0) if the gesture/attitude was not present, (1) if observed occasionally, and (2) if observed frequently. A score summing the values for each behavior was then created for each guideline.

${ }^{b}$ Guideline 1: Showing love.

Guideline 2: Following child's lead.

Guideline 3: Verbal and non-verbal communication.

Guideline 4: Praising and appreciating what the child manages to do.

Guideline 5: Helping the child to focus his attention and share his experiences.

Guideline 6: Helping the child to make sense of his world.

Guideline 7: Helping the child to widen his experience.

Guideline 8a: Helping the child to learn rules, limits and values.

Guideline 8b: Accompanies the child to learn step by step.

guideline at 12 months, controlling for receiving the intervention. We found that the application of Guideline 8a (firmly correcting the child providing options and explanations), and $8 \mathrm{~b}$ (accompanying the child step by step when trying something new) significantly decreased the risk of language delay (Table 7).

\section{DISCUSSION}

Children from deprived urban settlements are typically at higher risk of developmental delay, lower achievement, and 
TABLE 5 | Multiple logistic regression analysis for worsening or persistence of food insecurity at the end of the project.

\begin{tabular}{lcccc}
\hline $\begin{array}{l}\text { Worsening or persistence of food } \\
\text { insecurity }\end{array}$ & ARR \pm SE & 95\% Cl & p-value & Model \\
\hline Received interventions & $0.20 \pm 0.09$ & $0.08,0.51$ & 0.0001 & $n=199$ \\
Child stress score & $1.64 \pm 0.20$ & $1.29,2.09$ & $<0.0001$ & $p<0.0001$ \\
Number of pets in the household & $1.73 \pm 0.38$ & $1.13,2.66$ & 0.004 & Pseudo $R^{2}=0.199$ \\
Maternal education, years & $0.91 \pm 0.01$ & $0.89,0.93$ & 0.017 & VIF $=1.05$ \\
& & & & Condition number: 10.45 \\
\hline
\end{tabular}

Adjusted risk ratios (ARR) are reported.

TABLE 6 | Multiple logistic regression analysis for (A) motor delay, (B) social/cognitive delay and (C) language delay at the end of the project.

\begin{tabular}{|c|c|c|c|c|}
\hline A: Motor delay & $\mathrm{ARR} \pm \mathrm{SE}$ & $95 \% \mathrm{Cl}$ & $p$-value & Model \\
\hline Received interventions & $0.76 \pm 0.41$ & $0.26,2.22$ & 0.619 & \multirow{4}{*}{$\begin{array}{c}n=197 \\
p=0.0008 \\
\text { Pseudo } R^{2}=0.225 \\
\text { VIF }=1.07 \\
\text { Condition number: } 4.65\end{array}$} \\
\hline Micronutrient intake & $0.12 \pm 0.09$ & $0.03,0.56$ & 0.004 & \\
\hline Child stress score & $1.36 \pm 0.24$ & $0.95,1.93$ & 0.097 & \\
\hline Pets in the home (number) & $3.24 \pm 1.31$ & $1.47,7.14$ & 0.0005 & \\
\hline Received interventions & $1.71 \pm 0.99$ & $0.54,5.35$ & 0.342 & \multirow{5}{*}{$\begin{array}{c}n=197 \\
p=0.0031 \\
\text { Pseudo } R^{2}=0.198 \\
\text { VIF }=1.08 \\
\text { Condition number: } 11.88\end{array}$} \\
\hline Micronutrient intake & $0.39 \pm 0.23$ & $0.13,1.24$ & 0.108 & \\
\hline \# pets in the home & $2.72 \pm 0.99$ & $1.33,5.55$ & 0.0004 & \\
\hline Child's stress scale & $1.33 \pm 0.21$ & $0.97,1.83$ & 0.082 & \\
\hline Maternal education (years) & $1.28 \pm 0.18$ & $0.96,1.69$ & 0.300 & \\
\hline Age (months) & $0.97 \pm 0.004$ & $0.96,0.98$ & 0.009 & \multirow{2}{*}{$\begin{array}{c}n=197 \\
p=0.0004 \\
\text { Pseudo } R^{2}=0.107 \\
\text { VIF }=1.01 \\
\text { Condition number: } 7.50\end{array}$} \\
\hline Diarrheal episodes in the last month (number) & $1.77 \pm 0.49$ & $1.03,3.04$ & 0.064 & \\
\hline
\end{tabular}

Adjusted risk ratios (ARR) are reported ${ }^{\text {. }}$.

${ }^{a}$ For each dependent variable, the analysis was based on whether the developmental delay was detected at 12 months regardless of status at baseline.

more behavioral and emotional problems than children living in more favored contexts $(38,39)$, and interventions that normally work in other communities are not as useful for children from slums, as observed for nutritional programs (40). This study of a semi-urbanized population living in conditions of poverty with limited access to water-sanitation and other government services identified multiple risk factors that may preclude children from fully achieving their potential from among environmental, infectious and poverty-related stressors. Our interventions were led by CHPs selected from among parents within our IC who learned and transmitted the methodology to other caregivers using a "step-by-step" learning system. Both subjective and objective evaluation revealed that caregivers and their children had benefitted from the training as our focus on community/home gardens, workshops on conscious nutrition and promotion of parenting skills using ICDP methodology positively impacted child development. At baseline, food insecurity, diarrhea and respiratory infections were common but all were lowered following the intervention.
The benefit on food insecurity persisted after controlling for multiple confounders. We also observed, at baseline, that $16.4 \%$ of children in the study had not achieved one or more of the age-specific developmental milestones. Following our combined interventions, this percentage declined. Furthermore, receiving the interventions reduced the risk of language delay. Two factors not linked to the intervention also influenced the risk of motor and social/cognitive delay: the intake of MMN decreased the risk of motor delay but having more pets increased it. More pets was also a risk factor for social/cognitive delay. Our proof of concept showed that a multi-sectorial approach can improve early child development in marginalized communities.

\section{Community-Based Participatory Research: The Impact on CHPs and Caregivers}

The fundamentals of participatory research were critical to the implementation of this multi-sectorial study. The bidirectional communication between high- and low/medium-income countries through our project ensured that our research was 


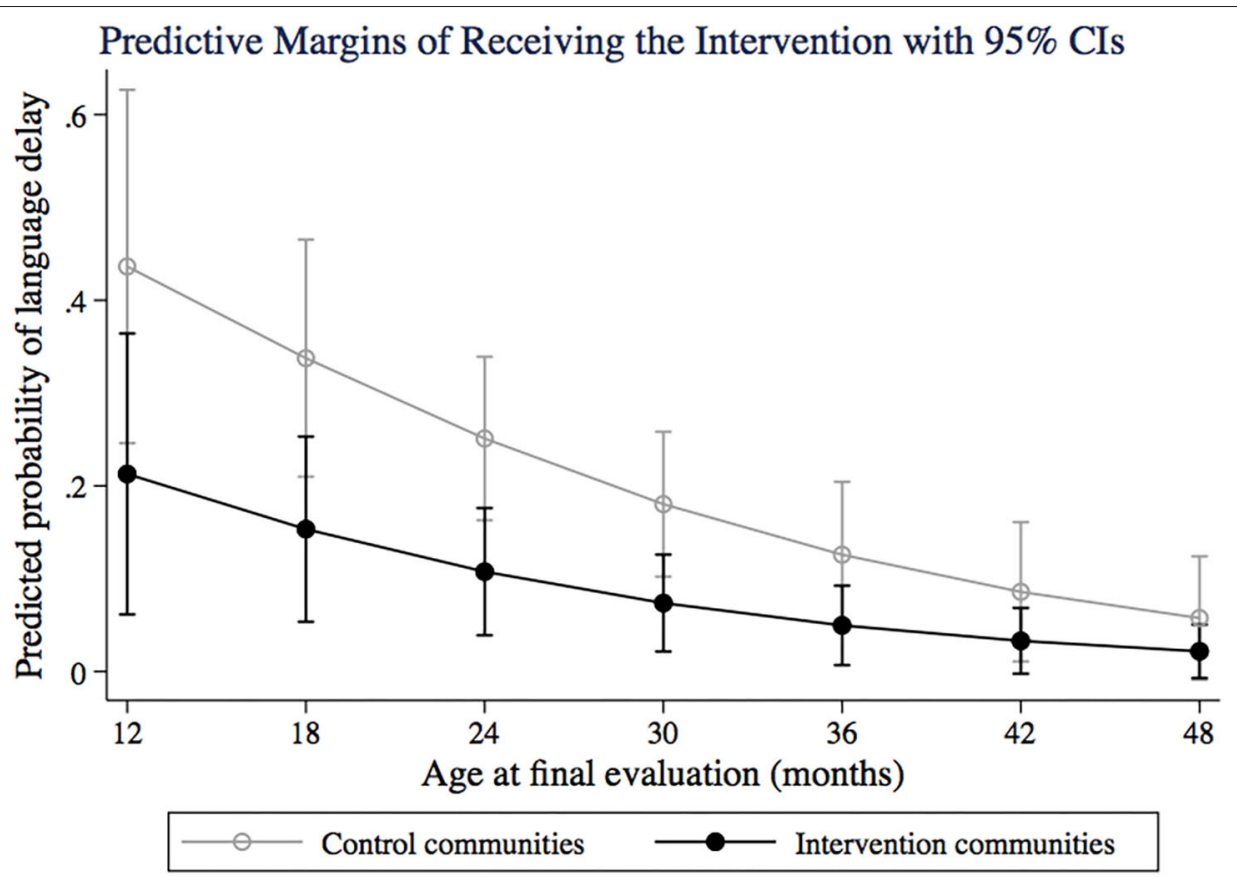

FIGURE 4 | Predictive probability of language delay for control and intervention communities, at different age groups (12-50 months). Predictive margins are adjusted by number of diarrheic episodes in the last month.

grounded in social justice (41). Consistent with participatory research, our project focused on the mutual learning relationship between the international and local project team, the nurses, and the CHPs. This allowed the methodology to reach the most vulnerable families and provided us with valuable information on both obvious and hidden needs of these communities. Our work adds to evidence suggesting that interventions that promote nurturing care can be included as part of basic community and public health interventions (4). A review of communitybased interventions for optimizing early childhood in low resource settings highlighted the importance of caregiver-child interactions (42). We confirmed this and expanded it to include gardens and nutritional components.

In order to go beyond cultural elements to reach individuals in targeted communities, interventions were modified to fit capacities of the project team and community settings (41). In addition, two new evaluation tools were developed. Our child stress instrument allowed us to identify and quantify stress in young children, to observe that stress was associated not only with an episode of violence but also with other unidentified causes, and to detect the association of child stress with food insecurity. Furthermore, borderline associations of child stress with motor and social/cognitive developmental delay show the need to consider child stress in future studies. Our novel checklist for evaluating caregiver-child interactions allowed us to objectively evaluate the ICDP methodology given that video recording used in previous studies (28) was not possible. This revealed the improvement of parenting skills in our IC but also in the CC.
One benefit of the project was the empowerment, enhanced communication skills and increase in self-confidence of the CHPs, gained through workshops with project experts and reinforced in their weekly visits to their families. This not only benefitted caregivers but also transformed the lives of the CHPs. At the end of the project, one CHP was hired by the community public health center to be a public health worker. Two had the courage to end an abusive partner relationship, and another started her own door-to-door egg business as a result of the confidence she gained in approaching people through her training and weekly educational visits to families. One CHP with a handicapped child agreed to do a presentation on ICDP to a regional gathering of parents of handicapped children because the program directors had heard her present to her own local support group. One was pregnant during the project and was able to apply all the methodology at home with her new baby. Families turned to them as resources for health and parenting information and were recognized by local authorities for their capacities. In parallel with their empowerment comes a responsibility to financially remunerate the time and efforts of CHPs that were the foundation for building community capacity. The multiple health risks that CHPs face in reaching remote households and during the wave of community violence in daily activities should be balanced with institutional support and CHPs should not be expected to perform their work on a voluntary basis. As has been noted by many others, the enhanced skills and abilities of CHPs need to be formally recognized financially $(43,44)$. The sustained caregiver engagement over the duration of the project suggests that the project was sustainable. 
TABLE 7 | Logistic regression models for the risk of language delay and the cumulative score for all attitudes associated with each guideline as observed by nurses watching caregivers interacting with their child, applying ICDP guidelines controlling for type of community (control vs. intervention).

\begin{tabular}{|c|c|c|c|}
\hline Language delay & $A R R \pm S E$ & $95 \% \mathrm{Cl}$ & $p$-value \\
\hline Showing love (Guideline 1, score) & $0.93 \pm 0.07$ & $0.81,1.07$ & 0.468 \\
\hline $\begin{array}{l}\text { Following child's lead (Guideline 2, } \\
\text { score) }\end{array}$ & $0.88 \pm 0.08$ & $0.74,1.05$ & 0.315 \\
\hline $\begin{array}{l}\text { Verbal and non-verbal } \\
\text { communication (Guideline 3, score) }\end{array}$ & $0.99 \pm 0.06$ & $0.88,1.2$ & 0.936 \\
\hline $\begin{array}{l}\text { Praising and appreciating what the } \\
\text { child manages to do } \\
\text { (Guideline } 4 \text {, score) }\end{array}$ & $0.80 \pm 0.10$ & $0.62,1.03$ & 0.197 \\
\hline $\begin{array}{l}\text { Helping the child to focus his } \\
\text { attention and share his experiences } \\
\text { (Guideline } 5 \text {, score) }\end{array}$ & $0.79 \pm 0.10$ & $0.62,1.01$ & 0.167 \\
\hline $\begin{array}{l}\text { Helping the child to make sense of } \\
\text { his world } \\
\text { (Guideline } 6, \text { score) }\end{array}$ & $0.90 \pm 0.09$ & $0.74,1.10$ & 0.375 \\
\hline $\begin{array}{l}\text { Helping the child to widen his } \\
\text { experience } \\
\text { (Guideline } 7, \text { score) }\end{array}$ & $0.90 \pm 0.07$ & $0.77,1.05$ & 0.273 \\
\hline $\begin{array}{l}\text { Helping the child to learn rules, } \\
\text { limits and values } \\
\text { (Guideline } 8 \mathrm{a} \text {, score) }\end{array}$ & $0.73 \pm 0.06$ & $0.62,0.85$ & 0.010 \\
\hline $\begin{array}{l}\text { Accompanies the child to learn step } \\
\text { by step } \\
\text { (Guideline } 8 b, \text { score) }\end{array}$ & $0.81 \pm 0.04$ & $0.73,0.91$ & 0.024 \\
\hline
\end{tabular}

Adjusted risk ratios (ARR) \pm standard errors (SE) and 95\% confidence intervals are reported.

Gestures/behavior observed to evaluate the presence of ICDP guides.

Guideline 1: the caregiver caresses, kisses, hugs, comforts the child.

Guideline 2: demonstrates interest in what the child does, is sensitive to child's intentions, plays what the child proposes.

Guideline 3: speaks to the child, smiles at him, looks at him in the eye, communicates at child's level of understanding, uses empathic tone of voice.

Guideline 4: praises what the child does well, encourages him.

Guideline 5: attracts his attention, joins child's interests.

Guideline 6: names objects, colors, counts numbers.

Guideline 7: gives explanations about the surroundings, makes comparisons, sings songs, tells stories.

Guideline 8a: when correcting the child, the caregiver presents options, provides explanations and is firm.

Guideline 8b: when the child tries to do something new, the caregivers accompanies the child in what he does, explains step by step, lets him try his best, provides support without interfering and accompanies child to achieve child's goal. Bold numbers indicate significant differences at $p<0.05$.

\section{Food Insecurity as a Target of the Interventions}

Food insecurity is a known determinant of inadequate child growth $(45,46)$, and a reduction in food insecurity was an important achievement of the project, probably attributable to the creation of home gardens. There is growing evidence that home gardens have a positive impact on children's diet diversity, anthropometry (11), infectious diseases (47) and anemia (48). Although, home gardens were not associated with food security in a study from the Philippines (49), in the present study we showed a significant association of the combined intervention including gardens, on food security. Our study supports the fact that simple interventions could mitigate the impact of the conditions of extreme poverty and adverse circumstances on child development.

\section{Language Development}

Interventions aimed at increasing children's stimulation can have a significant impact on language development (50). Although ICDP methodology was key for achieving the improvement of early child language development, besides its proven effect on parental skills $(51,52)$ and on decreasing difficulties in older children (52), ours is the first study to provide evidence that the ICDP methodology reduces the risk of language delay in children under five. We attribute this to the emphasis on treating the child as a person, giving the child a role in everyday family life, and explaining to the child what exists and happens in the environment (28). Among ICDP guidelines, the two belonging to the regulative dialogue $(8 \mathrm{a}, 8 \mathrm{~b})$ emerged as determinants in reducing the risk of language delay. Those guidelines involve clear and articulate communication with explanations of why and consequences. Furthermore, ICDP guidelines were applied to concrete day-to-day activities such as meals and gardening times. Giving quality food, with a feeling of love, as well as the participation of children (when they were old enough) in the planting and preparation of food was also reinforced throughout the project.

Broader factors are also involved in language development. A recent meta-analysis of risk factors for developmental delay in low-medium income countries identified that lower maternal education was associated with lower child cognitive scores, that lack of access to clean water and sanitation was associated with lower cognitive and motor development, and that lack of clean water was associated with lower language scores but that diarrhea was not significantly associated with development (53). Interestingly, our nutrition and garden workshops were associated with a reduction in episodes of both diarrhea and respiratory infections, and furthermore the number of diarrheal episodes in the month prior to our final evaluation had a borderline impact on increasing the risk of language delay. This suggests that the reduction in language delay may be associated with improvements in child health due to the nutrition interventions. This would align with a Brazilian study showing that early childhood diarrhea was associated with impaired fluency of language (54), and with an Haitian study where a link between nutritional factors (breastfeeding and complementary feeding frequencies, dietary diversity, egg and oil intake) and reduced infectious diseases improved language outcomes (55). Giving that early language development predicts future speech, grammar, reading, academic achievement and intelligence (56), our study provides evidence that our feasible intervention may have long-term benefits for children in these communities.

\section{Importance of Non-intervention Realities (MMN and Pets) on Child Development}

An unexpected finding was that higher number of pets was associated with increased risk of motor and social/cognitive delay. Comparisons between communities showed that IC children had more dogs and cats at their homes, whereas CC 
children were more frequently exposed to vermin. Both pets (57) and vermin are vectors of infectious diseases (58-61). A study in Argentina identified that a greater number of people and animals (dogs, cats, chickens) in the home was associated with a greater infestation and abundance of disease-transmitting insects (61), but the association of the presence of pets with increased risk of areas of developmental delay has not been reported before. Domestic animal control may constitute a neglected preventable risk factor for child's health.

\section{Lessons Learned}

This project recognized that mothers from the communities who were trained as CHPs were effective agents of social change. Wawa Illari taught us the value of empowering mothers independent of their educational level with tools that benefit themselves and their families.

Working with people in disadvantaged communities requires empathy, trust and flexibility. We learned that some community processes, such as CHPs' and caregivers' learning rhythms and creating trust and bonds with the community cannot be forced or rushed. The "step-by-step" learning system was key for achieving effectiveness in the practical application of concepts in gardens, hygiene, balanced meal preparation and appropriate caregiver child interaction.

Methodologies and field delivery systems need to be adapted to local capacities and field realities. Our monitoring and learning system revealed the importance of ongoing adaptation to changing situations including the inclusion of new institutional partners and implementing delivery mechanisms to reach intervention families.

There were situations of intra-family violence that discouraged CHPs from approaching violent households. The CHP, with our help, was able to understand that each family was a complex world. By listening to, learning from and adapting to CHPs and families' learning rhythm, schedules and routines we managed to implement a highly personalized and impactful project.

In order to reach the most vulnerable, we had to work within a parallel informal economy, weakly functioning institutions, and lack of basic water and sanitation infrastructure. Given that some communities lived in territories under no official state jurisdiction, they were not covered by legal benefits. Although out of the scope of our intervention, we realized that without local policies that improve essential community services, no intervention would be sufficiently effective for children to achieve their full potential.

\section{Strengths and Limitations}

We were able to demonstrate an impact on food security, frequency of diarrheal and respiratory infections, and on language development. Indirect impacts of improving nutrition and caregiver-child interactions were observed through changes toward healthier feeding practices with increased intake of nutrients that are essential for child development, the treatment of parasitic infections and the support of MINSA policies regarding frequent growth and development follow up and intake of MMN. However, the 12-month timeframe of intervention may have been too short to demonstrate significant changes in traditional anthropometry indicators.

Initial differences between IC and CC made it more challenging to attribute changes directly to the intervention.

The Wawa Illari project was developed amid adverse circumstances, where frequent changes of health authorities at national and regional levels during the time of the project made administrative processes difficult. Political instability precluded us from reaching and making agreements with health authorities at the national level. Fortunately, constant communication with CHPs, support from local health authorities and health personnel, and family commitment to the methodology facilitated the resumption of activities and the continuity of the project.

\section{CONCLUSION}

Through this multisector intervention that included home gardens, conscious nutrition workshops, and parenting skill development, we were able to demonstrate improvement in food security and language development in young children within a 12 months period, despite unfavorable field and institutional conditions. The success was in part attributed to on-site adaptations to adjust to changing local circumstances. The study highlights the value of framing indictors to the broad spheres of early motor, social/cognitive and language development. Importantly, we showed that training CHPs using the "step-by-step" learning system was effective for helping them to learn key messages and also to have a methodology for delivery of health-related knowledge and skills to caregivers in a way that allowed them to integrate activities into their daily life.

\section{DATA AVAILABILITY STATEMENT}

Given the highly sensitive local political situation and in order to protect the privacy of our vulnerable population, the datasets for this article are not publicly available. Participants did not sign informed consent that data will be publicly available, neither was this possibility discussed with Ethical Boards in Peru or Canada. Requests to access the datasets should be directed to Dr. Kristine G. Koski (kristine.koski@mcgill.ca).

\section{ETHICS STATEMENT}

The studies involving human participants were reviewed and approved by Institutional Committee on Research Ethics of the National Institute for Child Health (registration OEAIDE-029972017), Lima, Peru. Written informed consent to participate in this study was provided by the participants' legal guardian/next of kin. Project received secondary approval by the Research Ethics Board at McGill University (REB File \#144-0817). 


\section{AUTHOR CONTRIBUTIONS}

DG-F, AM, VT, KK, and MS participated in study design. DG-F, AM, KK, MS, and CG participated in adaptation of questionnaires and acquisition of ethical approvals. DG-F coordinated data collection, ran statistical analyses, and performed statistical analyses. AM led field coordination and implementation including continuous training and monitoring of CHPs in the three methodologies, field accounting, and administration. AM and FH led the ICDP methodology. FH supported field coordination and implementation and helped with administrative field activities. IP participated in recruitment of CHPs, trainer of trainers for gardens' intervention, implemented the planting of fruit trees, and obtained additional funding. EG did training of trainers in conscious nutrition. NA provided continuous advice to local ICDP activities. VT did the international administration of the project and directly involved in principal and supplementary funding acquisition. SV facilitated introductory access to communities and the recruitment process. SH was the liaison-nurse with Pachacámac health authorities and verified technical accuracy of data collection. BR prepared logistics, analysed, and reported data on intestinal parasites. CG provided pediatric advice. DG-F, IP, AM, FH, VT, MS, and KK wrote the paper. All authors read and approved the content of the paper.

\section{FUNDING}

This project was funded by Saving Brains, Grand Challenges Canada with grant \#R-SB-POC-1707-09076. Complementary funding came from Susila Dharma (SD) International, SD Canada, SD US, SD UK, from the Aspen Community Foundation (US), the Subud Enterprises Services Fund and the McGill Graduate Excellence Fellowship Award. Graduate Excellence Award \#00071.

\section{ACKNOWLEDGMENTS}

Saving Brains, a branch of Grand Challenges Canada, supported operational and administrative aspects. The project benefited

\section{REFERENCES}

1. Figueiras AC, Neves de Souza IC, Ríos VG, Benguigui Y. Monitoring Child Development (0-6 Years) in the IMCI Context. (2012). Available online at: https://www.google.com/url?sa= $\mathrm{t} \& \mathrm{rct}=\mathrm{j} \& \mathrm{q}=\& \mathrm{esrc}=\mathrm{s} \&$ source $=$ web $\& \mathrm{~cd}=1 \& \mathrm{cad}=\mathrm{rja} \& \mathrm{uact}=8 \& \mathrm{ved}=$ 2ahUKEwiOzf7Zwb3pAhWJmHIEHbSvD8gQFjAAegQIAhAB\& url=https $\% 3 \mathrm{~A} \% 2 \mathrm{~F} \% 2 \mathrm{Fwww}$.paho.org\%2Fhq\%2Fdmdocuments $\% 2$ F2017\%2Fchild-development-monitoring-imci.pdf\&usg= AOvVaw0KuDBTT3d23dGm38DXUjDX (accessed May 15, 2019).

2. Black MM, Walker SP, Fernald LCH, Andersen CT, DiGirolamo AM, Lu C, et al. Early childhood development coming of age: science through the life course. Lancet. (2017) 389:77-90. doi: 10.1016/S0140-6736(16)31389-7

3. McCoy DC, Peet ED, Ezzati M, Danaei G, Black MM, Sudfeld CR, et al. Early childhood developmental status in low- and middle-income countries: national, regional, and global prevalence estimates using predictive modeling. PLoS Med. (2016) 13:e1002034. doi: 10.1371/journal.pmed.1002034 from independent donors to Susila Dharma Canada, Susila Dharma International, and the Aspen Community Foundation via a donor advised fund run by Adam and Melony Lewis. Thanks also to Ana María Álvarez, for her work in accounting and financial reporting for donors, and to Raphaelle Chapleau who facilitated the initial administrative processes. The project would not have been possible without the collaboration of the nurses Milagro Cuya (Manchay health center), Zarela Cuya (Las Palmas health center) and Yolanda Román (San Juan health center), led by Ms. Gloria Alcántara, as well as the CHPs, who were the voice and hands of the project with families: Hilda Apaza, Milagros Salvador, Nilda Zarate, Jenny Paredes, Rossemary Huaman, Wilmer Saavedra, Nelly Ruiz, Rosa Vargas, Lourdes Padilla, Liseth Julca, Leodomila Martínez, Norah Melchor, Sonia Yañe, Eddy Melchor, and Kelinda Martinez (gardens' supervisor). To them our most sincere thanks. Also many thanks to Stefanny Purizaca and Chiara Núñez for their timely and dedicated support in the creation of the database.

Special thanks to the nursing faculty of the Inca Garcilaso de la Vega University, especially to Luz Medrano, for her support in enrolling participants, to the engineer Renán Valega, who supported the design, provided the seeds and supported the first stages of the creation of the gardens, Loa Mellares, who supported with the interview of participants, and all the personnel of the health centers of Las Palmas, Manchay and San Juan, who directly or indirectly facilitated the evaluation of the project participants. Many thanks to Walter Prötzel for housing, transport and logistics support.

Finally, thanks to the families that participated in the project, to the hours dedicated to receiving the workshops and to their commitment to attend the evaluations, and especially to the families of the control community, who were constant despite not receiving the methodology.

\section{SUPPLEMENTARY MATERIAL}

The Supplementary Material for this article can be found online at: https://www.frontiersin.org/articles/10.3389/fpubh. 2020.567900/full\#supplementary-material
4. Richter LM, Daelmans B, Lombardi J, Heymann J, Boo FL, Behrman JR, et al. Investing in the foundation of sustainable development: pathways to scale up for early childhood development. Lancet. (2017) 389:103-18. doi: 10.1016/S0140-6736(16) 31698-1

5. de Onis M, Dewey KG, Borghi E, Onyango AW, Blossner M, Daelmans B, et al. The World Health Organization's global target for reducing childhood stunting by 2025: rationale and proposed actions. Matern Child Nutr. (2013) 9(Suppl. 2):6-26. doi: 10.1111/mcn.12075

6. McDougall L. Discourse, ideas and power in global health policy networks: political attention for maternal and child health in the millennium development goal era. Global Health. (2016) 12:21. doi: 10.1186/s12992-016-0157-9

7. Bhutta ZA, Guerrant RL, Nelson CA, III. Neurodevelopment, nutrition, and inflammation: the evolving global child health landscape. Pediatrics. (2017) 139(Suppl. 1):S12-22. doi: 10.1542/peds.20162828D 
8. Cook JT, Frank DA. Food security, poverty, and human development in the United States. Ann N Y Acad Sci. (2008) 1136:193-209. doi: 10.1196/annals.1425.001

9. Moron C. Food-based nutrition interventions at community level. Br J Nutr. (2006) 96(Suppl. 1):S20-2. doi: 10.1079/BJN20061693

10. Chadare FJ, Madode YE, Fanou-Fogny N, Kindossi JM, Ayosso JO, Honfo $\mathrm{SH}$, et al. Indigenous food ingredients for complementary food formulations to combat infant malnutrition in Benin: a review. J Sci Food Agric. (2018) 98:439-55. doi: 10.1002/jsfa.8568

11. Marquis GS, Colecraft EK, Kanlisi R, Aidam BA, Atuobi-Yeboah A, Pinto $\mathrm{C}$, et al. An agriculture-nutrition intervention improved children's diet and growth in a randomized trial in Ghana. Matern Child Nutr. (2018) 14(Suppl. 3):e12677. doi: $10.1111 / \mathrm{mcn} .12677$

12. Kar BR, Rao SL, Chandramouli BA. Cognitive development in children with chronic protein energy malnutrition. Behav Brain Funct. (2008) 4:31. doi: $10.1186 / 1744-9081-4-31$

13. Yadav D, Chandra J. Iron deficiency: beyond anemia. Indian J Pediatr. (2011) 78:65-72. doi: 10.1007/s12098-010-0129-7

14. Millward DJ. Nutrition, infection and stunting: the roles of deficiencies of individual nutrients and foods, and of inflammation, as determinants of reduced linear growth of children. Nutr Res Rev. (2017) 30:5072. doi: $10.1017 / S 0954422416000238$

15. Oria RB, Murray-Kolb LE, Scharf RJ, Pendergast LL, Lang DR, Kolling GL, et al. Early-life enteric infections: Relation between chronic systemic inflammation and poor cognition in children. Nutr Rev. (2016) 74:37486. doi: $10.1093 /$ nutrit/nuw008

16. Gera T, Shah D, Sachdev HS. Impact of water, sanitation and hygiene interventions on growth, non-diarrheal morbidity and mortality in children residing in low- and middle-income countries: a systematic review. Indian Pediatr. (2018) 55:381-93. doi: 10.1007/s13312-018-1279-3

17. Leiser $\mathrm{K}$, Heffelfinger A, Kaugars A. Associations among parentchild relationships and cognitive and language outcomes in a clinical sample of preschool children. Clin Neuropsychol. (2017) 31:423-37. doi: 10.1080/13854046.2016.1268649

18. Onnis L. Caregiver communication to the child as moderator and mediator of genes for language. Behav Brain Res. (2017) 325:197202. doi: 10.1016/j.bbr.2017.02.003

19. Chao HC, Chang HL. Picky eating behaviors linked to inappropriate caregiver-child interaction, caregiver intervention, and impaired general development in children. Pediatr Neonatol. (2017) 58:22-8. doi: 10.1016/j.pedneo.2015.11.008

20. Garcia D, Rodriquez GM, Hill RM, Lorenzo NE, Bagner DM. Infant language production and parenting skills: a randomized controlled trial. Behav Ther. (2019) 50:544-57. doi: 10.1016/j.beth.2018.09.003

21. Begin F, Frongillo EA, Jr., Delisle H. Caregiver behaviors and resources influence child height-for-age in rural Chad. J Nutr. (1999) 129:6806. doi: $10.1093 / \mathrm{jn} / 129.3 .680$

22. Martorell $\mathrm{R}$, Zongrone A. Intergenerational influences on child growth and undernutrition. Paediatr Perinat Epidemiol. (2012) 26(Suppl. 1):30214. doi: 10.1111/j.1365-3016.2012.01298.x

23. Britto PR, Lye SJ, Proulx K, Yousafzai AK, Matthews SG, Vaivada T, et al. Nurturing care: Promoting early childhood development. Lancet. (2017) 389:91-102. doi: 10.1016/S0140-6736(16)31390-3

24. MINSA. Directiva Sanitaria que Establece la Suplementación con Micronutrientes y Hierro Para la Prevención de Anemia en Niñas y Niños Menores de 36 Meses. (2014). Available online at: https://www.google. $\mathrm{com} / \mathrm{url}$ ? sa $=\mathrm{t} \& \mathrm{rct}=\mathrm{j} \& \mathrm{q}=\&$ esrc $=\mathrm{s} \&$ source $=$ web $\& \mathrm{~cd}=7 \& \mathrm{ved}=2 \mathrm{ahUKEwi}-$ jdm1hKbjAhXDl-AKHbDYAPkQFjAGegQIAxAC\&url=https\%3A\%2F \%2Fwww.minsa.gob.pe\%2FEspecial\%2F2015\%2FNutriwawa\%2Fdirectivas \%2F001DS_Suplem_MultiMicro.pdf\&usg=AOvVaw2Ul06oIvbD4Iee_6rCZ_Q (accessed July 8, 2019).

25. Dean AG SK, Soe MM. Tamaño Muestral: Transversal, de Cohorte, y Ensayo Clínico. (2019). Available online at: https://www.openepi.com/Menu/OE_ Menu.htm (accessed July 4, 2019).

26. Galarza M. Cultura de Crianza. 2nd Edn. Quito: Galarza-Izquierdo (2012).

27. WHO. Improving Mother/Child Interaction to Promote Better Psychosicial Development in Children. (1997). Available online at: http://www.who.int/ mental_health/media/en/29.pdf (accessed June 24, 2019).
28. Hundeide K, Armstrong N. Icdp approach to awareness-raising about children's rights and preventing violence, child abuse, and neglect. Child Abuse Negl. (2011) 35:1053-62. doi: 10.1016/j.chiabu.2011.09.008

29. Figueiras AM, Neves de Souza IC, Ríos VG, Benguigui Y. Manual Para la Vigilancia del Desarrollo Infantil (0-6 años) en el Contexto de AIEPI. Washington, DC: PAHO (2011). Available online at: http://wwwl.paho. org/hq/dmdocuments/manual-vigilancia-desarrollo-infantil-aiepi-2011.pdf. (accessed May 15, 2019).

30. MINSA Perú. Norma Técnica de Salud Para el Control de Crecimiento y Desarrollo de la Niña y el Niño Menor de Cinco Años. (2011). Available online at: http://datos.minsa.gob.pe/dataset/control-de-crecimiento-y-desarrollode-ninos-menores-de-5-anos/resource/8067fbaf-8323-4bc0 (accessed July 4, 2019).

31. Sotelo N, Vásquez-Arteaga L, González-Fernández D, Marín-Agudelo N, González-Cuellar F, Montero-Carvajal J, et al. Situación del parasitismo intestinal en preescolares de un hogar infantil estatal en Popayán, Colombia. Med Lab. (2017) 23:573-7. doi: 10.36384/01232576.8

32. Salvatierra-Ruiz R, Cárdenas-Achata L. Recetario Nutritivo Para Niñas y Niños de 6 a 23 Meses. Lima: Ministerio de Salud del Perú, Instituto Nacional de Salud. (2014). Available online at: http://www.ins.gob.pe/repositorioaps/0/5/ par/prub_rec/recetario_de_ninos_final.pdf

33. Cafiero C, Melgar-Quinonez HR, Ballard TJ, Kepple AW. Validity and reliability of food security measures. Ann N Y Acad Sci. (2014) 1331:23048. doi: 10.1111/nyas. 12594

34. WHO. Training Course on Child Growth Assessment. (2008). Available online at: https://www.who.int/childgrowth/training/en/ (accessed May 15, 2019).

35. Vidmar SI, Cole TJ, Pan H. Standardizing anthropometric measures in children and adolescents with functions for egen: update. Stata J. (2013) 13:366-78. doi: 10.1177/1536867X1301300211

36. Engle-Stone R, Aaron GJ, Huang J, Wirth JP, Namaste SM, Williams $\mathrm{AM}$, et al. Predictors of anemia in preschool children: biomarkers reflecting inflammation and nutritional determinants of anemia (BRINDA) project. Am J Clin Nutr. (2017) 106(Suppl. 1):402s-15s. doi: 10.3945/ajcn. 117.999

37. Norton EC, Miller MM, Kleinman LC. Computing adjusted risk ratios and risk differences in stata. Stata J. (2013) 13:492509. doi: 10.1177/1536867X1301300304

38. Johnson SB, Riis JL, Noble KG. State of the art review: poverty and the developing brain. Pediatrics. (2016) 137:e20153075. doi: 10.1542/peds.2015-3075

39. Nair MK, Radhakrishnan SR. Early childhood development in deprived urban settlements. Indian Pediatr. (2004) 41:227-37.

40. Goudet SM, Bogin BA, Madise NJ, Griffiths PL. Nutritional interventions for preventing stunting in children (birth to 59 months) living in urban slums in low- and middle-income countries (LMIC). Cochrane Database Syst Rev. (2019) 6:CD011695-CD. doi: 10.1002/14651858.CD011695.pub2

41. Baumann AA, Mejia A, Lachman JM, Parra Cardona JR, LópezZerón G, Amador Buenabad NG, et al. Parenting programs for underserved populations in low- and middle-income countries: issues of scientific integrity and social justice. Glob Soc Welf. (2019) 6:199-207. doi: 10.1007/s40609-018-0121-0

42. Maulik PK, Darmstadt GL. Community-based interventions to optimize early childhood development in low resource settings. J Perinatol. (2009) 29:531-42. doi: 10.1038/jp.2009.42

43. Agarwal S, Kirk K, Sripad P, Bellows B, Abuya T, Warren C. Setting the global research agenda for community health systems: literature and consultative review. Hum Resour Health. (2019) 17:22. doi: 10.1186/s12960-0190362-8

44. Scott K, Beckham SW, Gross M, Pariyo G, Rao KD, Cometto G, et al. What do we know about community-based health worker programs? A systematic review of existing reviews on community health workers. Hum Resour Health. (2018) 16:39. doi: 10.1186/s12960-018-0304-x

45. Saha KK, Frongillo EA, Alam DS, Arifeen SE, Persson LA, Rasmussen KM. Household food security is associated with growth of infants and young children in rural Bangladesh. Public Health Nutr. (2009) 12:155662. doi: $10.1017 /$ S1368980009004765

46. French B, Outhwaite LA, Langley-Evans SC, Pitchford NJ. Nutrition, growth, and other factors associated with early cognitive and motor development 
in Sub-Saharan Africa: a scoping review. J Hum Nutr Diet. (2020) 33:64469. doi: 10.1111/jhn.12795

47. English RM, Badcock JC, Giay T, Ngu T, Waters AM, Bennett SA. Effect of nutrition improvement project on morbidity from infectious diseases in preschool children in Vietnam: comparison with control commune. BMJ. (1997) 315:1122-5. doi: 10.1136/bmj.315.7116.1122

48. Michaux KD, Hou K, Karakochuk CD, Whitfield KC, Ly S, Verbowski V, et al. Effect of enhanced homestead food production on anaemia among Cambodian women and children: a cluster randomized controlled trial. Matern Child Nutr. (2019) 15(Suppl. 3):e12757. doi: 10.1111/mcn.12757

49. Cabalda AB, Rayco-Solon P, Solon JA, Solon FS. Home gardening is associated with Filipino preschool children's dietary diversity. J Am Diet Assoc. (2011) 111:711-5. doi: 10.1016/j.jada.2011.02.005

50. Aboud FE, Yousafzai AK. Global health and development in early childhood. Annu Rev Psychol. (2015) 66:43357. doi: 10.1146/annurev-psych-010814-015128

51. Sherr L, Skar AM, Clucas C, von Tetzchner S, Hundeide K. Evaluation of the International Child Development Programme (ICDP) as a community-wide parenting programme. Eur J Dev Psychol. (2014) 11:1-17. doi: 10.1080/17405629.2013.793597

52. Skar AM, von Tetzchner S, Clucas C, Sherr L. The long-term effectiveness of the International Child Development Programme (ICDP) implemented as a community-wide parenting programme. Eur J Dev Psychol. (2015) 12:5468. doi: 10.1080/17405629.2014.950219

53. Sania A, Sudfeld CR, Danaei G, Fink G, McCoy DC, Zhu Z, et al. Early life risk factors of motor, cognitive and language development: a pooled analysis of studies from low/middle-income countries. BMJ Open. (2019) 9:e026449. doi: 10.1136/bmjopen-2018-026449

54. Patrick PD, Oriá RB, Madhavan V, Pinkerton RC, Lorntz B, Lima AA, et al. Limitations in verbal fluency following heavy burdens of early childhood diarrhea in Brazilian shantytown children. Child Neuropsychol. (2005) 11:23344. doi: 10.1080/092970490911252

55. Iannotti L, Jean Louis Dulience S, Wolff P, Cox K, Lesorogol C, Kohl P. Nutrition factors predict earlier acquisition of motor and language milestones among young children in haiti. Acta Paediatr. (2016) 105:e40611. doi: 10.1111/apa.13483
56. Bornstein MH, Hahn C-S, Putnick DL, Pearson RM. Stability of core language skill from infancy to adolescence in typical and atypical development. Sci Adv. (2018) 4:eaat7422. doi: $10.1126 /$ sciadv.aat7422

57. Irwin PJ. Companion animal parasitology: a clinical perspective. Int $J$ Parasitol. (2002) 32:581-93. doi: 10.1016/S0020-7519(01)00361-7

58. Collinet-Adler S, Babji S, Francis M, Kattula D, Premkumar PS, Sarkar $\mathrm{R}$, et al. Environmental factors associated with high fly densities and diarrhea in Vellore, India. Appl Environ Microbiol. (2015) 81:60538. doi: 10.1128/AEM.01236-15

59. Farag TH, Faruque AS, Wu Y, Das SK, Hossain A, Ahmed $S$, et al. Housefly population density correlates with shigellosis among children in Mirzapur, Bangladesh: a time series analysis. PLoS Negl Trop Dis. (2013) 7:e2280. doi: 10.1371/journal.pntd. 0002280

60. Wright CE, el Alamy M, DuPont HL, Holguin AH, Hsi BP, Thacker $\mathrm{SB}$, et al. The role of home environment in infant diarrhea in rural Egypt. Am J Epidemiol. (1991) 134:887-94. doi: 10.1093/oxfordjournals.aje. a116163

61. Gurevitz JM, Ceballos LA, Gaspe MS, Alvarado-Otegui JA, Enriquez GF, Kitron $U$, et al. Factors affecting infestation by Triatoma infestans in a rural area of the humid Chaco in Argentina: a multi-model inference approach. PLoS Negl Trop Dis. (2011) 5:e1349. doi: 10.1371/journal.pntd.00 01349

Conflict of Interest: The authors declare that the research was conducted in the absence of any commercial or financial relationships that could be construed as a potential conflict of interest.

Copyright (๑) 2020 González-Fernández, Mazzini Salom, Herrera Bendezu, Huamán, Rojas Hernández, Pevec, Galarza Izquierdo, Armstrong, Thomas, Vela Gonzáles, Gonzáles Saravia, Scott and Koski. This is an open-access article distributed under the terms of the Creative Commons Attribution License (CC BY). The use, distribution or reproduction in other forums is permitted, provided the original author(s) and the copyright owner(s) are credited and that the original publication in this journal is cited, in accordance with accepted academic practice. No use, distribution or reproduction is permitted which does not comply with these terms. 